\title{
Mesoscale Convective Vortex that Causes Tornado-Like Vortices over the Sea: A Potential Risk to Maritime Traffic
}

\author{
EIGO Tоснімото \\ Atmosphere and Ocean Research Institute, The University of Tokyo, Tokyo, Japan \\ SHO YокотA \\ Meteorological Research Institute, Japan Meteorological Agency, Tsukuba, Japan \\ HIROSHI NIINO \\ Atmosphere and Ocean Research Institute, The University of Tokyo, Tokyo, Japan \\ WATARU YANASE \\ Meteorological Research Institute, Japan Meteorological Agency, Tsukuba, Japan
}

(Manuscript received 24 August 2018, in final form 28 January 2019)

\begin{abstract}
Strong gusty winds in a weak maritime extratropical cyclone (EC) over the Tsushima Strait in the southwestern Sea of Japan capsized several fishing boats on 1 September 2015. A C-band Doppler radar recorded a spiral-shaped reflectivity pattern associated with a convective system and a Doppler velocity pattern of a vortex with a diameter of $30 \mathrm{~km}$ [meso- $\beta$-scale vortex (MBV)] near the location of the wreck. A highresolution numerical simulation with horizontal grid interval of $50 \mathrm{~m}$ successfully reproduced the spiralshaped precipitation pattern associated with the MBV and tornado-like strong vortices that had a maximum wind speed exceeding $50 \mathrm{~m} \mathrm{~s}^{-1}$ and repeatedly developed in the MBV. The simulated MBV had a strong cyclonic circulation comparable to a mesocyclone in a supercell storm. Unlike mesocyclones associated with a supercell storm, however, its vorticity was largest near the surface and decreased monotonically with increasing height. The strong vorticity of the MBV near the surface originated from a horizontal shear line in the EC. The tornado-like vortices developed in a region of strong horizontal shear in the western part of the MBV, suggesting that they were caused by a shear instability.
\end{abstract}

\section{Introduction}

Violent winds associated with tornadoes have a serious impact on society, causing significant damage to structures and fatalities. Tornadoes often occur in association with large-scale atmospheric disturbances such as extratropical cyclones (ECs) (e.g., Newton 1967; Miller 1972; Johns and Doswell 1992) and tropical cyclones (e.g., Novlan and Gray 1974; McCaul 1991; Sueki and Niino 2016) the horizontal scales of which are on the order of $1000 \mathrm{~km}$. For ECs, the warm sector to the south of the EC center, between cold and warm fronts, is known to be a favorable region for supercell storms that

\footnotetext{
Corresponding author: Eigo Tochimoto, tochimoto@aori.utokyo.ac.jp
}

often spawn tornadoes (e.g., Newton 1967; Miller 1972; Johns and Doswell 1992; Roebber et al. 2002 ; Corfidi et al. 2010; Tochimoto and Niino 2016, 2017, 2018). Supercell storms are accompanied by strong updrafts associated with mid- and low-level mesocyclones (Browning 1964; Lemon and Doswell 1979; Klemp and Rotunno 1983), which have a diameter of 2-10 km.

At around 0300 Japan standard time (JST $=$ UTC + 9h) 1 September 2015, strong gusty winds occurred over the Tsushima Strait about $100 \mathrm{~km}$ northeast of the center of a relatively weak EC with central sea level pressure (SLP) of $1004 \mathrm{hPa}$, and capsized six fishing boats, causing five fatalities (Fig. 1a). According to an AsahiShimbun newspaper, some of the survived fishermen reported that they were hit by violent rotating winds 
(a) Weather map 03 JST 1 Sep. 2015

(b)
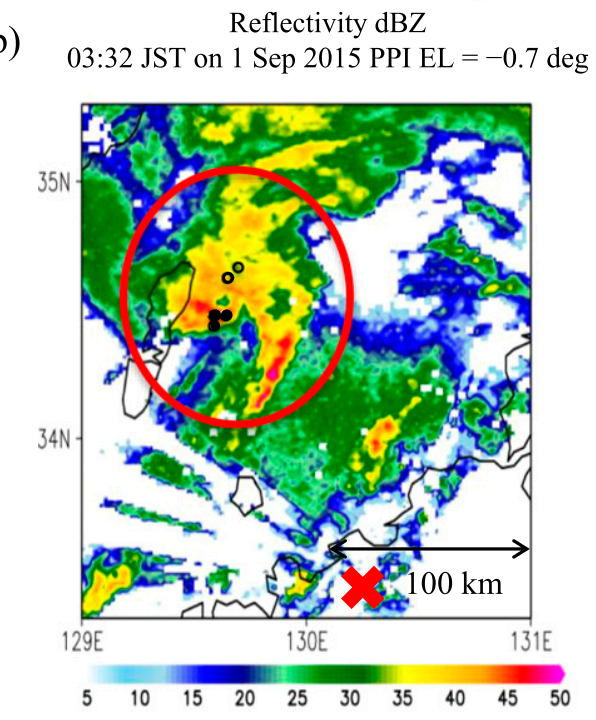

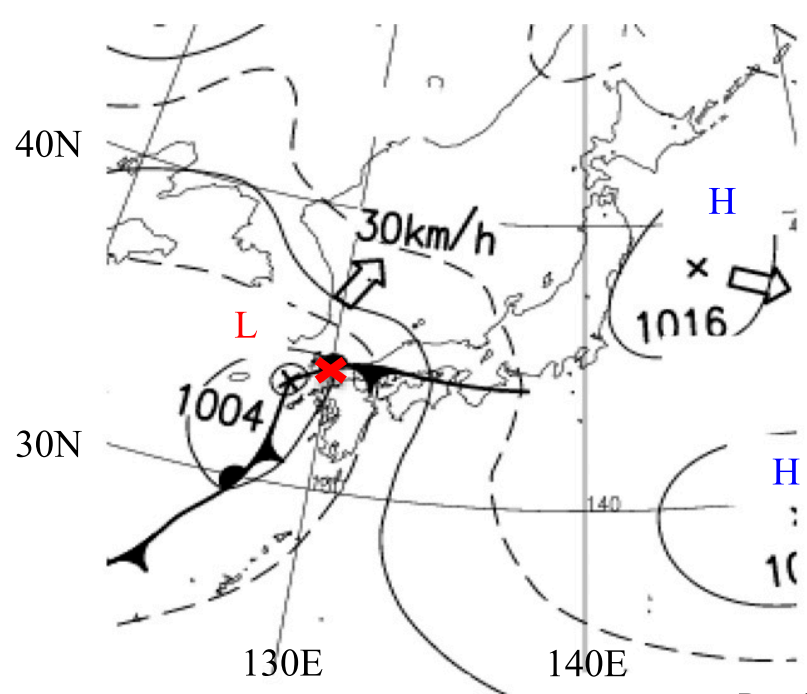

Doppler Velocity m s${ }^{-1}$
(c) 03:32 JST on 1 Sep 2015 PPI EL $=-0.3 \mathrm{deg}$

FIG. 1. Observed characteristics of the meso- $\beta$ vortex on 1 Sep 2015. (a) Surface weather map at 0300 JST.(b) Radar reflectivity (dBZ) and (c) Doppler velocity $\left(\mathrm{m} \mathrm{s}^{-1}\right.$ ) observed by the JMA Fukuoka C-band Doppler radar at 0332 JST. A red cross in (a) indicates the location of the shipwrecks, and red crosses in (b) and (c) indicate the location of the Fukuoka radar. Black filled circles in (b) and (c) indicate the locations of shipwrecks between 0320 and 0335 JST. Black open circles in (b) and (c) indicate the locations of shipwrecks at around 0355 JST.

possibly due to tornado-like vortices. The Japan Meteorological Agency (JMA) Fukuoka Doppler radar, located about $130 \mathrm{~km}$ southeast of the marine accidents, recorded a spiral-shaped precipitation system (Fig. 1b) in reflectivity, which propagated northward with time. The same radar observed a Doppler velocity pattern that clearly indicated a meso- $\beta$-scale vortex (MBV) with a diameter of about $30 \mathrm{~km}$ at 0330 JST (Fig. 1c). However, the Fukuoka radar was not able to see any tornado-like vortices since the horizontal resolution of the radar around the Tsushima Strait is about $1 \mathrm{~km}$.
Over the North American continent, a variety of hazardous mesoscale vortices associated with mesoscale convective systems (MCSs) have been observed: mesoscale convective vortices (MCVs; Zhang 1992; Fritsch et al. 1994; Trier and Davis 2002; Davis and Trier 2007; Davis et al. 2004; Davis and Galarneau 2009; Conzemius et al. 2007), which often form within MCSs such as quasilinear convective systems (QLCSs) and mesoscale convective complexes (MCCs; Maddox 1980; Menard and Fritsch 1989), have a typical horizontal scale between 100 and $300 \mathrm{~km}$ (Menard and Fritsch 1989). These MCVs tend to have their maximum strength in 
the midtroposphere. Line-end vortices that often form within the bow echo have horizontal scales of $10-100 \mathrm{~km}$ and are strongest at 2-4-km height (American Meteorological Society 2015). Mesovortices (Schenkman and Xue 2016), which are often observed within the leading edge of QLCSs such as bow echoes and derechos (Fujita 1978, 1979; Przybylinski 1995; Funk et al. 1999) and are closely linked with severe damaging winds and tornadoes (Atkins et al. 2004, 2005; Wakimoto et al. 2006a,b), have a typical horizontal scale between 2 and $20 \mathrm{~km}$ (i.e., meso- $\gamma$ scale; Orlanski 1975). The present MBV, which formed over the sea, had a horizontal scale larger than that of mesovortices and smaller than that of MCVs, and similar to line-end vortices.

Although the MBV that causes tornado-like vortices has a potential risk to maritime traffic, finescale structure and formation mechanism of the MBV have not been reported. Recent developments in computer technology and numerical models enable us to reliably reproduce mesoscale and microscale phenomena in the atmosphere (e.g., Mashiko et al. 2009; Mashiko 2016a, b). The purpose of this paper is to report on the formation mechanism and detailed structure of the MBV, and features of tornado-like vortices, as revealed by a high-resolution numerical simulation.

\section{Observed evolution of the convective system}

Evolution of a precipitation system observed by Fukuoka radar is shown in Fig. 2. From 2200 to 2300 JST 31 August 2015, a widespread precipitation area is found around Tsushima Strait (Figs. 2a and 2b). After that, active convective system started to develop in the southern part of the precipitation area at 0000 JST (Figs. 2c-e). At 0100 JST, a line-shaped reflectivity pattern $(\geq 40 \mathrm{dBZ})$ appeared in the region $33.5^{\circ}-$ $34.5^{\circ} \mathrm{N}, 128.5^{\circ}-130^{\circ} \mathrm{E}$ (Fig. $2 \mathrm{~d}$ ), and evolved into spiralshaped reflectivity pattern, which is a characteristic of the MBV, developed at 0300 JST (Fig. 2f). Although the feature of the line-shaped reflectivity pattern in the south of Tsushima Islands at 0100 JST (Fig. 2d) resembles that of bow-echo system, evolution of the system in the present case is somewhat different from book-end or line-end vortices: the MBV developed not in the northern end of the line-shaped convective system but in the central or southern part of the system (Figs. 2e and 2f).

Now, we examine the evolutions of Doppler velocity (Fig. 3). At 0100 JST, no clear signature of a vortex exists. In the early developing stage of the MBV (0130-0200 JST), a couplet of positive and negative Doppler velocity in the southwest $\left(34^{\circ} \mathrm{N}\right.$, $129^{\circ} \mathrm{E}$ ) implies the existence of a weak vortex with horizontal convergence. The velocity difference between the maximum and minimum radial velocities is about $20-30 \mathrm{~m} \mathrm{~s}^{-1}$ (around $34^{\circ} \mathrm{N}, 129.1^{\circ} \mathrm{E}$; Fig. 3b). At $0230 \mathrm{JST}$, the vortex located around $34.1^{\circ} \mathrm{N}, 129.3^{\circ} \mathrm{E}$ becomes evident (Fig. 3c) and the velocity difference becomes about $40-50 \mathrm{~m} \mathrm{~s}^{-1}$ around there. At this time, another couplet of positive and negative Doppler velocity in the east $\left(34.2^{\circ}-34.5^{\circ} \mathrm{N}, 129.4^{\circ}-\right.$ $129.7^{\circ} \mathrm{E}$ ) of Tsushima Island implies the existence of horizontal convergence. At $0300 \mathrm{JST}$, a couplet of positive and negative Doppler velocity, which characterizes a vortex flow associated with the MBV, is clearly detected in the southern part of the reflectivity pattern $\geq 40 \mathrm{dBZ}$ (around $34.2^{\circ} \mathrm{N}, 129.6^{\circ} \mathrm{E}$ ). At this time, the velocity difference becomes about $60-80 \mathrm{~m} \mathrm{~s}^{-1}$ (around $34.2^{\circ} \mathrm{N}, 129.6^{\circ} \mathrm{E}$ ). In the north of this couplet, a belt-shaped distribution of positive and negative Doppler velocity exists in the region of $34.3^{\circ}-34.7^{\circ} \mathrm{N}$, $129.5^{\circ}-130^{\circ} \mathrm{E}$, which indicates the existence of horizontal convergence and horizontal shear. The Doppler velocity pattern, which characterize the MBV, and its associated reflectivity pattern propagate northward (Fig. 3f).

Figure 4 shows time sequence of blackbody temperature (TBB) observed from the Geostationary Meteorological Satellite Himawari-8. Between 1200 and 1800 JST 31 August 2018, there is no region in which TBB is lower than $241 \mathrm{~K}$ around Tsushima Strait. At 2100 JST 31 August, a region in which TBB is lower than $221 \mathrm{~K}$ started to appear in the south of Tsushima Island. After that, this region started to spread around Tsushima Strait from 0000 JST 1 September 2015 (Figs. 4e and 4f), which is associated the intensification of the convective system (Figs. $2 d-f$ ). In the present case, there is no convective system that satisfies Maddox's definition of MCCs: cloud shield with continuously low IR temperature $\leq 241 \mathrm{~K}$ and cold cloud region with temperature $\leq 221 \mathrm{~K}$ did not have areas $\geq 100000 \mathrm{~km}^{2}$ and $\geq 50000 \mathrm{~km}^{2}$, respectively, for a period $\geq 6 \mathrm{~h}$ (Maddox 1980).

\section{Setting of the numerical experiments}

The numerical model used in the present study is the Japan Meteorological Agency Nonhydrostatic Model (JMANHM; Saito et al. 2006). The present study adopted the bulk-type cloud microphysics scheme (Ikawa et al. 1991; Murakami 1990), which predicts the mixing ratio of water vapor, cloud water, rain, cloud ice, snow, and graupel. Two kinds of numerical simulations are performed. The first simulation aims to examine the 
(a)

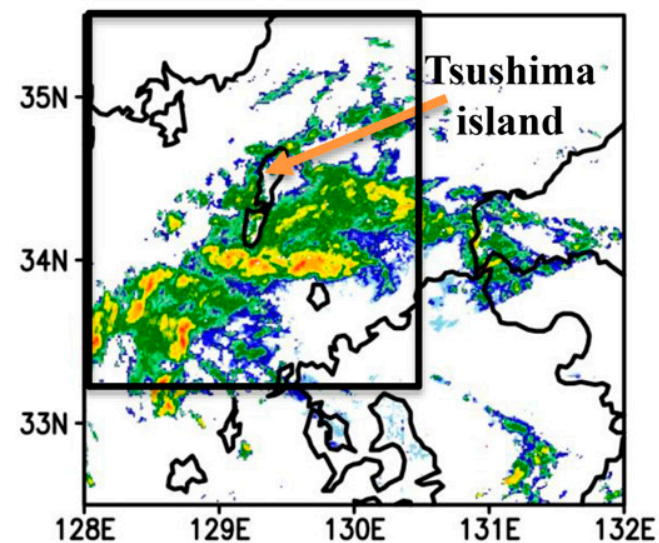

(c)

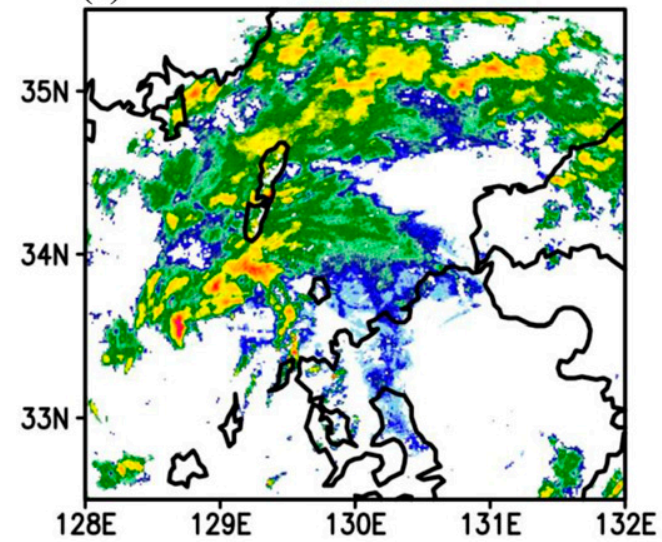

(e)

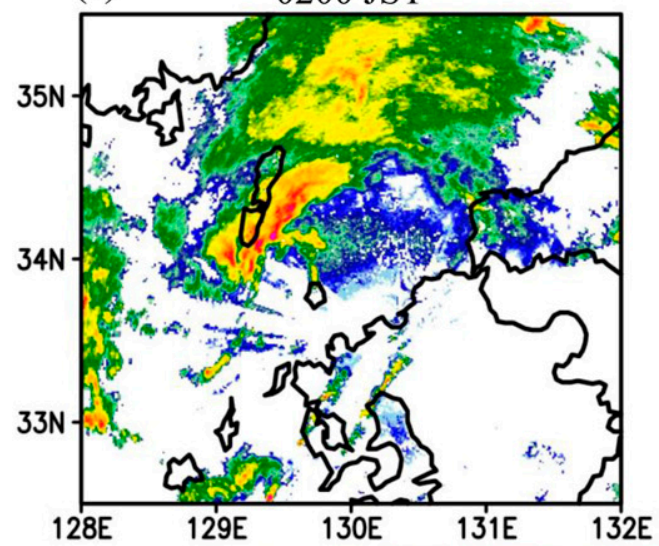

(b)

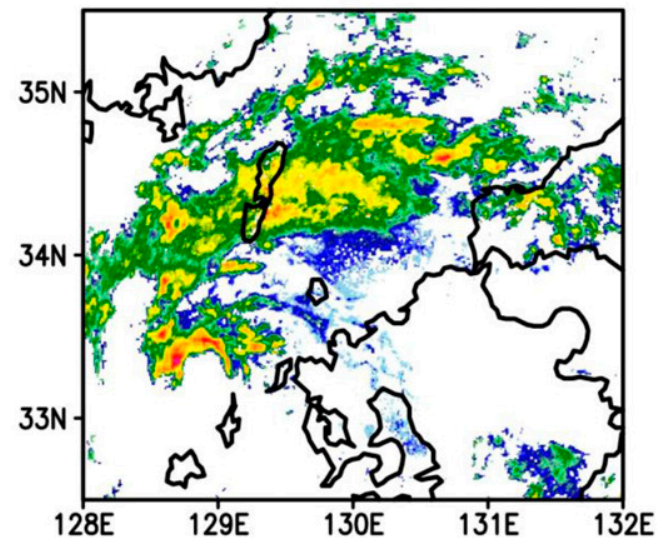

(d)

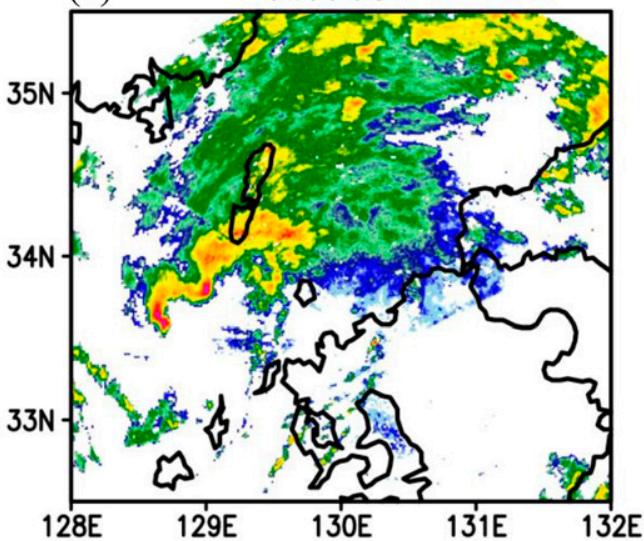

(f)

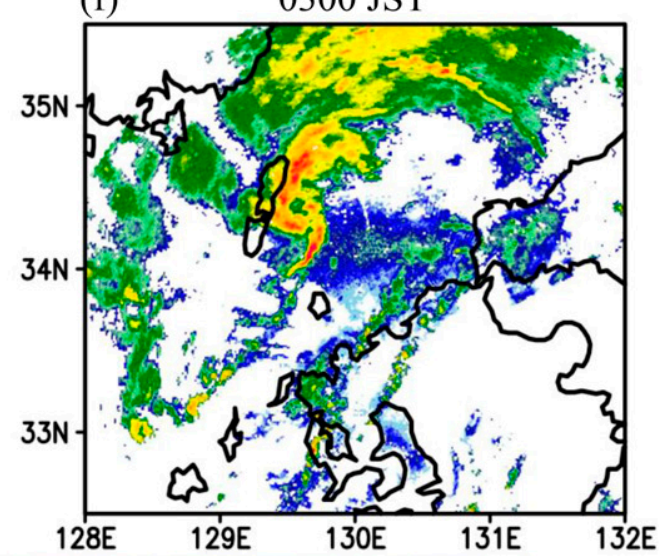

$128 \mathrm{E}$

\section{$\begin{array}{llllllllll}5 & 10 & 15 & 20 & 25 & 30 & 35 & 40 & 45 & 50\end{array}$}

FIG. 2. Radar reflectivity (dBZ) observed by the JMA Fukuoka C-band Doppler radar at (a) 2200 JST 31 Aug, (b) 230031 Aug, (c) 0000 JST 1 Sep, (d) 0100 JST 1 Sep, (e) 0200 JST 1 Sep, and (f) 0300 JST 1 Sep 2015. The box in (a) indicates the region in which Doppler velocity fields are drawn in Fig. 3.

formation and development processes of the MBV: a numerical model that covers a large area (Fig. 5a), with low horizontal resolution of $2 \mathrm{~km}(750 \times 750$ horizontal grid points; hereafter NHMF2km), is run from 1800 JST
31 August to 0500 JST 1 September 2015, which includes the period before the genesis of the MBV. The number of vertical levels is 50 . To accurately calculate the source of the near-surface vorticity, a numerical model with 
(a)
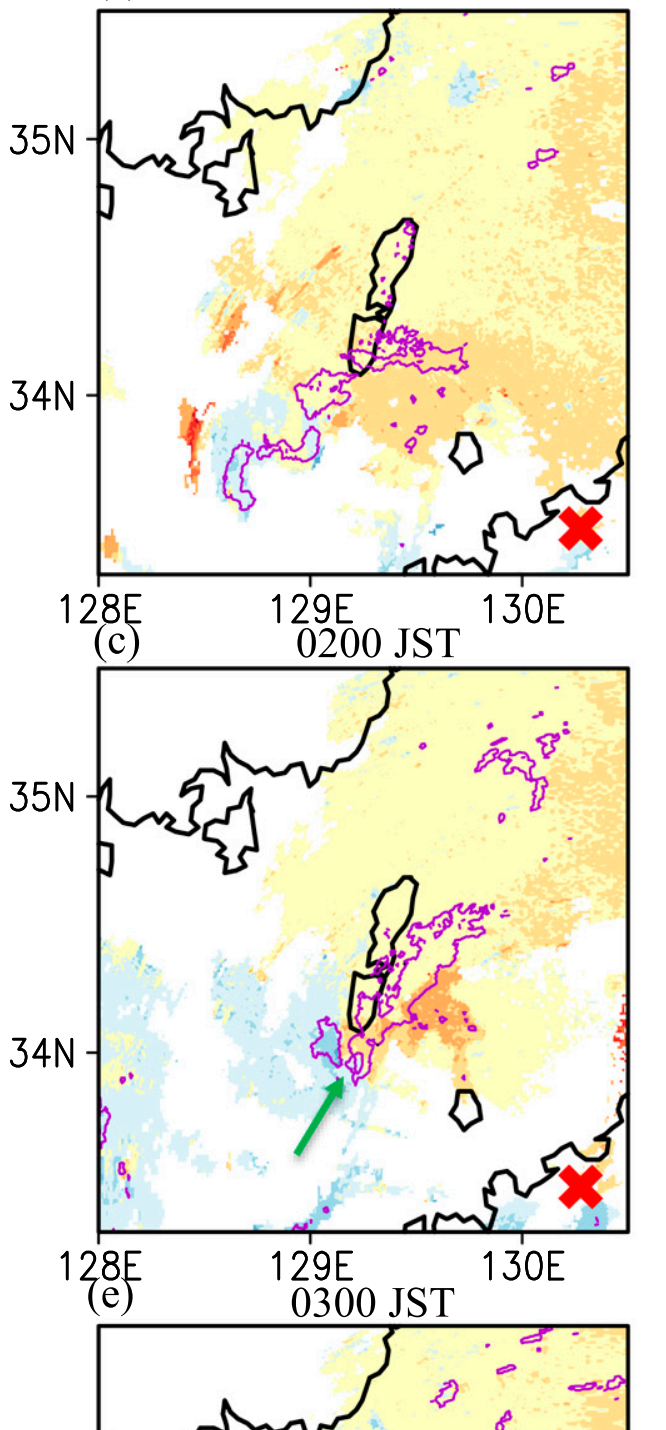

$35 \mathrm{~N}$

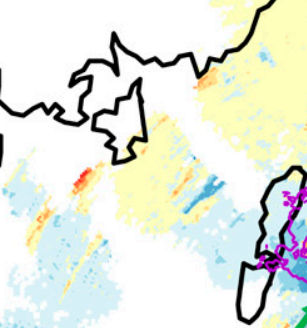

$34 \mathrm{~N}$

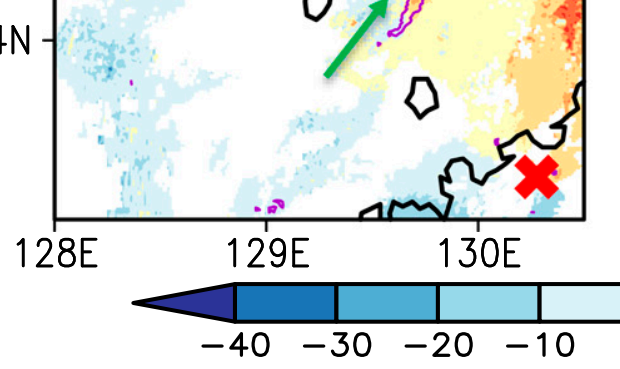

(b)

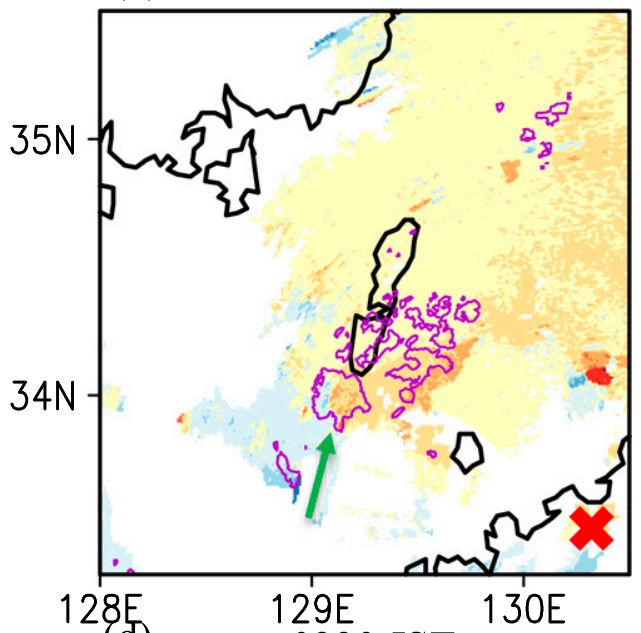

(d)
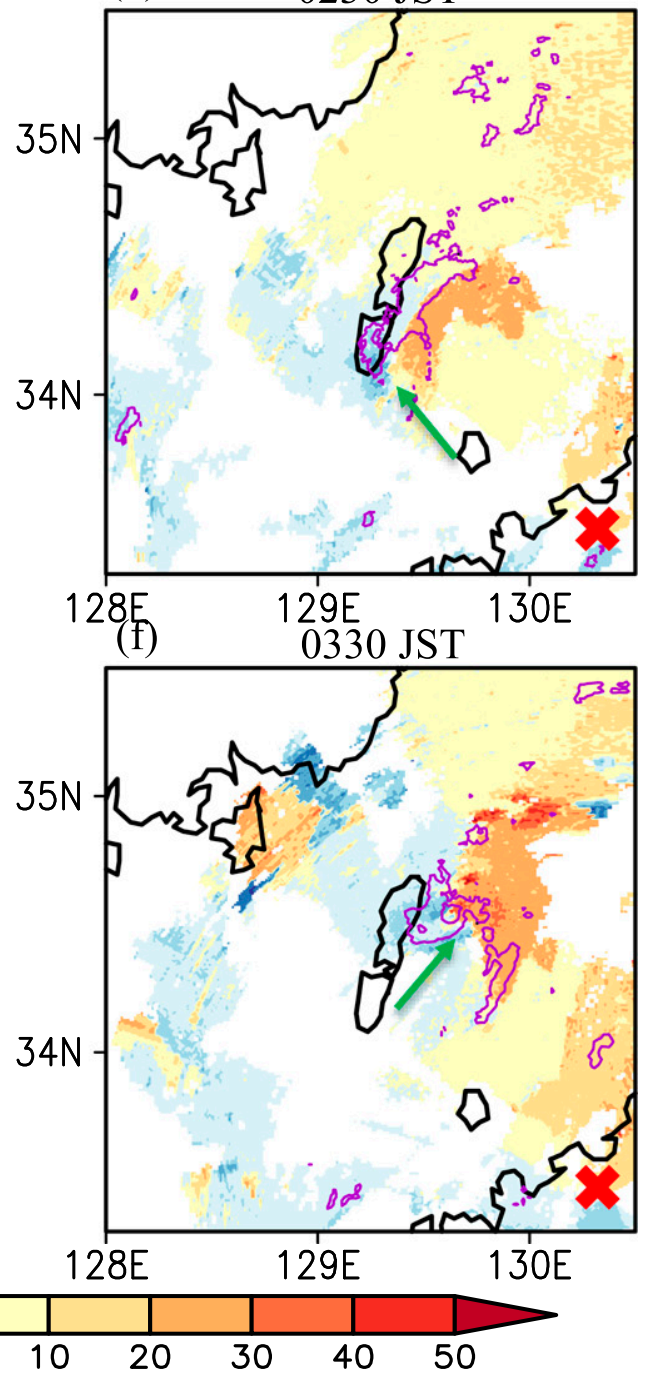

FIG. 3. Doppler velocity observed by the JMA Fukuoka C-band Doppler radar at (a) 0100 JST, (b) 0130 JST (c) 0200 JST, (d) 0230 JST, (e) 0300 JST, and (f) 0330 JST 1 Sep 2015. Note that purple contour lines indicate isolines of $40 \mathrm{dBZ}$. Red crosses indicate the position of Fukuoka Radar. 
(a) 1200 JST 31 Aug. 2015

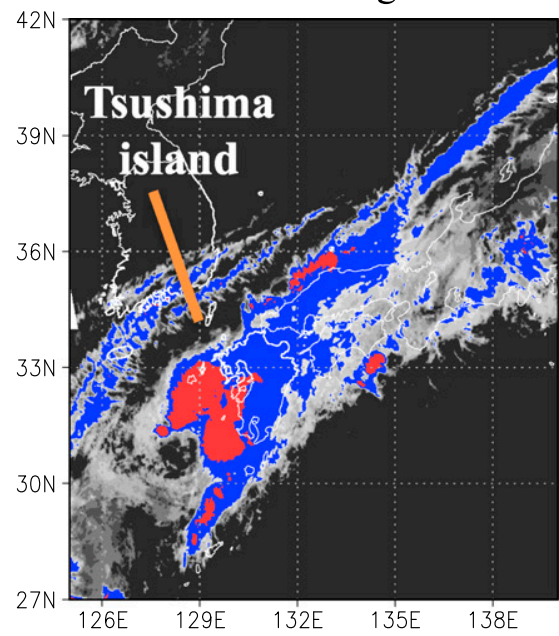

(c) 1800 JST 31 Aug. 2015

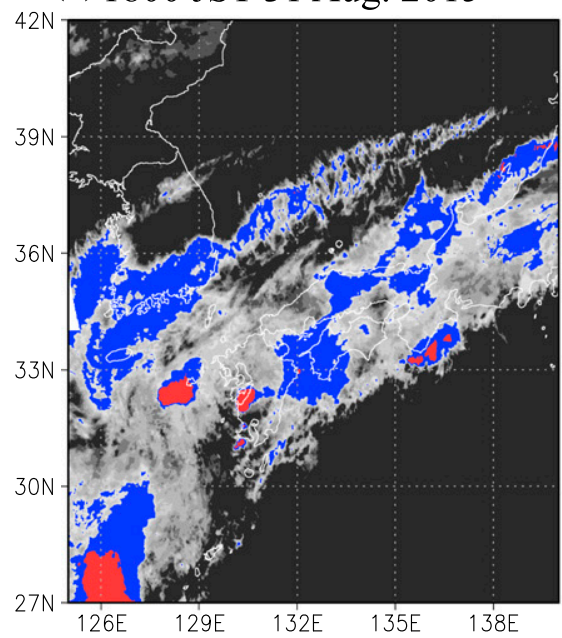

(e) 0000 JST 1 Sep. 2015

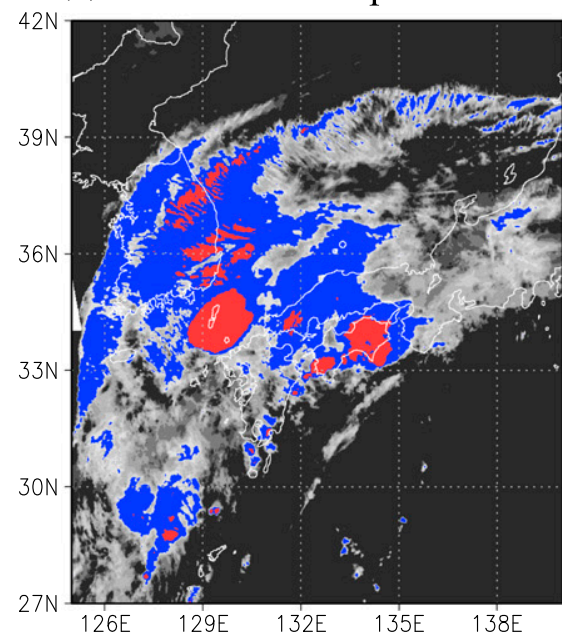

(b) 1500 JST 31 Aug. 2015

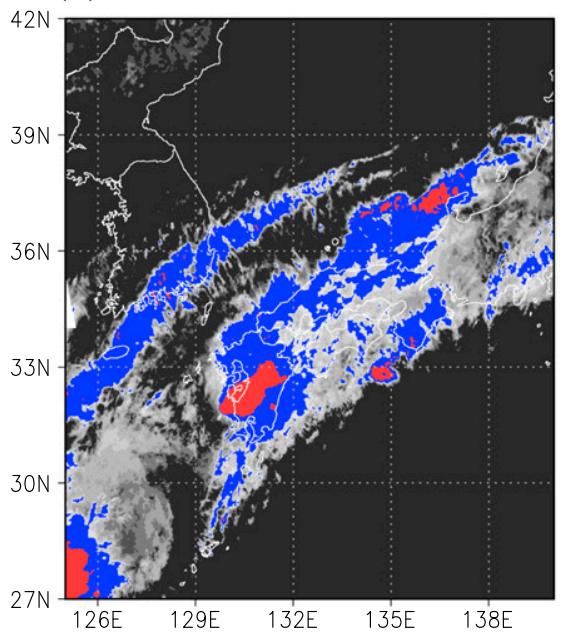

(d) 2100 JST 31 Aug. 2015

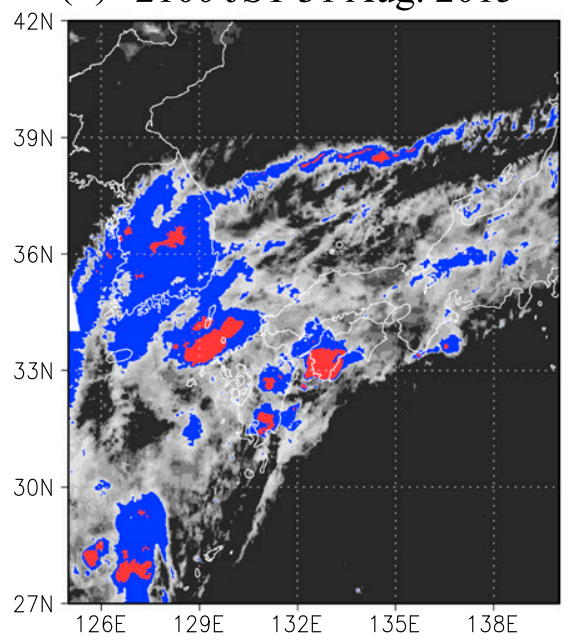

(f) 0300 JST 1 Sep. 2015

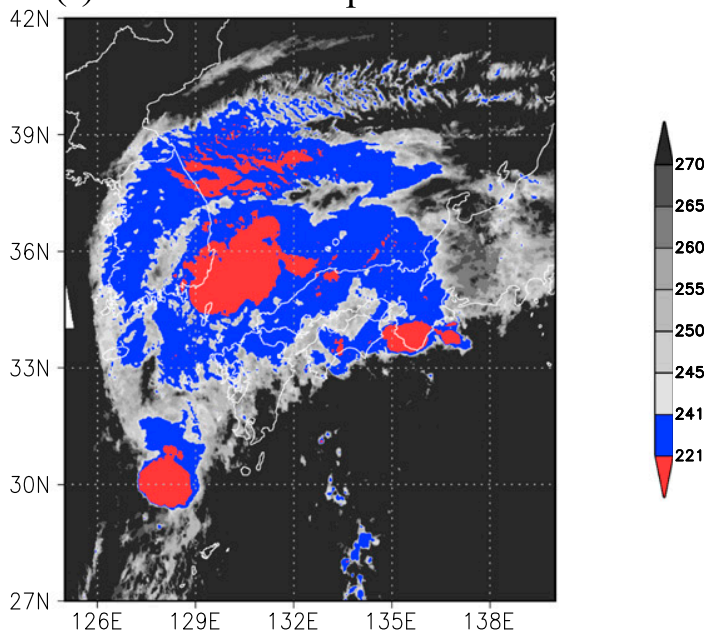

FIG. 4. Blackbody temperature observed from Himawari-8 at (a) 1200 JST 31 Aug, (b) 1500 JST 31 Aug, (c) 1800 JST 31 Aug, (d) 2100 JST 31 Aug, (e) 0000 JST 1 Sep, and (f) 0300 JST 1 Sep. 
(a) NHM $2 \mathrm{~km}$

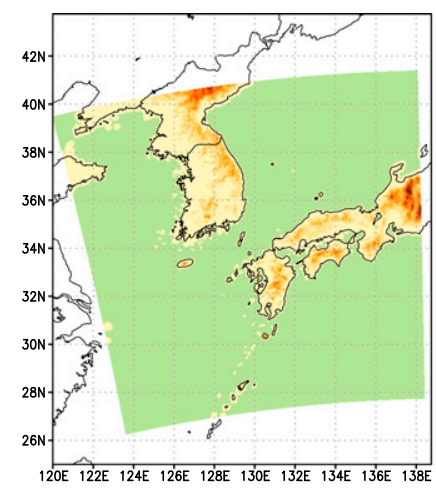

(b) NHM 350m

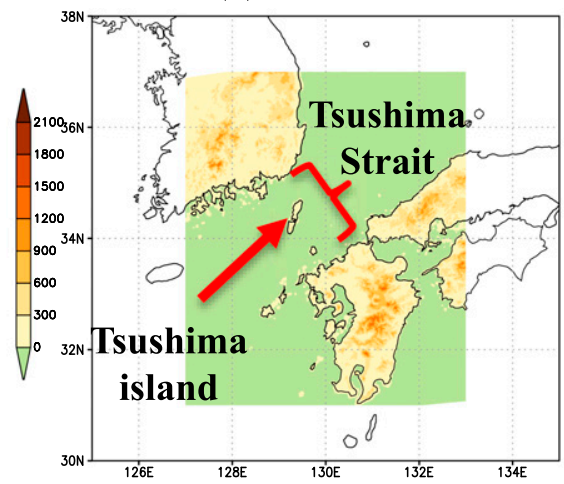

(c) NHM 50m

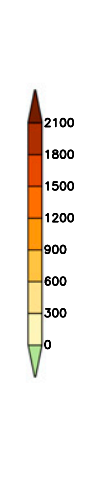

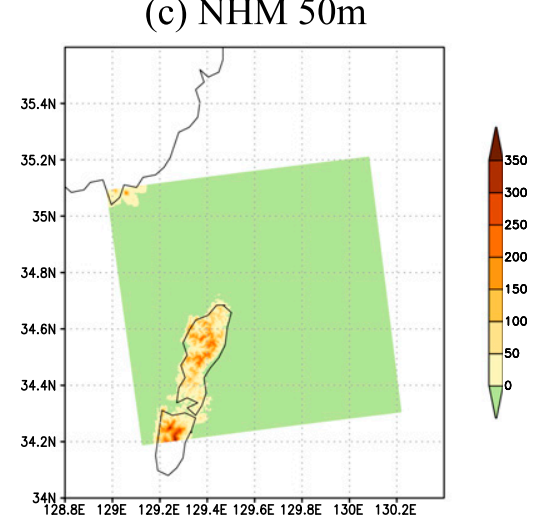

FIG. 5. Computational domains of (a) NHMF2km and NHMS2km, (b) NHMF350m and NHMS350m, and (c) NHMS50m, where color shading represents the heights of topography $(\mathrm{m})$ in the model. The locations of Tsushima island and Tsushima Strait are indicated in (b).

intermediate horizontal resolution of $350 \mathrm{~m}(2000 \times$ 2000 horizontal grid points; hereafter NHMF350m) and 70 vertical levels is nested (Fig. 5b) in the low-resolution model described above and is run from 0230 to 0430 JST 1 September 2015 (see Table 1). The vertical grid spacing of the model with the coarse (intermediate) horizontal resolution varies from $40 \mathrm{~m}$ at the lowest level to 900 (618) m near the top boundary.

The second simulation with a low-resolution $(2 \mathrm{~km})$ simulation (hereafter NHMS2km), in which intermediateand high-resolution models are nested, is started at 0000 JST 1 September (see Table 2). This is because the structure of the MBV reproduced by the second simulation better resembles the observation, and thus is hoped to better reproduce microscale disturbances embedded in the MBV. To investigate the detailed structure in the MBV, the high-resolution model with horizontal resolution of $50 \mathrm{~m}(2000 \times$ 2000 grid points; hereafter NHMS50m) and 100 vertical levels is nested (Fig. 5c) in the intermediate horizontal-resolution model with horizontal resolution of $350 \mathrm{~m}$ (hereafter NHMS350m), which is started from 0230 JST 1 September, and is run from 0330 JST 1 September. The vertical grid spacing of the highresolution model varies from $10 \mathrm{~m}$ at the lowest level to $443 \mathrm{~m}$ near the top boundary.
Physical settings for all simulations are same except for the boundary layer parameterizations: The MellorYamada-Nakanishi-Niino (MYNN) level-3 planetary boundary layer scheme (Nakanishi and Niino 2006) is adopted for the low-resolution simulations, while the Deardorff subgrid turbulence scheme (Deardorff 1980) is adopted for the intermediate- and highresolution simulations. Initial and boundary conditions for the low-resolution simulation are obtained from the 3-hourly JMA mesoscale analysis data with a horizontal grid spacing of $5 \mathrm{~km}$, which are operationally produced by a four-dimensional variational data assimilation technique.

\section{Results}

\section{a. Finescale structure of meso- $\beta$-scale vortex}

The NHMS50m successfully reproduces the essential features of the MBV including the spiral-shaped distribution of rainwater mixing ratio associated with the MBV (Fig. 6a), which is similar to the observation by the Fukuoka radar (Fig. 2f) except that the simulated MBV develops about an hour later and is located slightly north of the observed MBV. Figure 6b shows horizontal distributions of vertical vorticity at 30-m height and sea level pressure (SLP) within the MBV. Tornado-like

TABLE 1. Design of the first numerical simulation started from 1800 JST 31 Aug 2015.

\begin{tabular}{lcc}
\hline \hline & NHMF2km & NHMF350m \\
\hline Dimensions (zonal $\times$ meridional $\times$ vertical) & $750 \times 750 \times 50$ & $2000 \times 2000 \times 70$ \\
Horizontal grid spacing (m) & 2000 & 350 \\
Model top (m) & 22244 & 22244 \\
Vertical grid spacing (m) & $40-900$ & $40-618$ \\
Integration time & 1800 JST 31 Aug-0500 JST 1 Sep 2015 & $0230-0500$ JST 1 Sep 2015 \\
\hline
\end{tabular}


TABLE 2. Design of the second numerical simulation started from 0000 JST 1 Sep 2015.

\begin{tabular}{lccc}
\hline \hline & NHMS2km & NHMS350m & NHMS50m \\
\hline Dimensions (zonal $\times$ meridional $\times$ vertical) & $750 \times 750 \times 50$ & $2000 \times 2000 \times 70$ & $2000 \times 2000 \times 100$ \\
Horizontal grid spacing (m) & 2000 & 350 & 50 \\
Model top (m) & 22244 & 22244 & 22244 \\
Vertical grid spacing (m) & $40-900$ & $40-618$ & $10-443$ \\
Integration time & $0000-0500$ JST 1 Sep 2015 & $0230-0500$ JST 1 Sep 2015 & $0330-0500$ JST 1 Sep 2015 \\
\hline
\end{tabular}

vortices with strong vertical vorticity exceeding $0.5 \mathrm{~s}^{-1}$ are found near the surface. Each of the vortices is accompanied by a SLP minimum (Fig. 6b). These simulated tornado-like vortices repeatedly form, develop, and decay in the west of the MBV center, where a region of strong horizontal shear is present. A linear instability theory of a shear instability (e.g., Rayleigh 1894) suggests that the wavelength of the fastest-growing mode is $\sim 7.5$ times the width of the shear zone. The width of the strongest shear zone in the MBV is roughly estimated to be $\sim 100-150 \mathrm{~m}$ based on the zonal distributions of meridional wind meridionally averaged between $34.8225^{\circ}$ and $34.83^{\circ} \mathrm{N}$ (the rectangle in Fig. $7 \mathrm{a}$ ) at $30-\mathrm{m}$ height at 0440 JST (Fig. 7b). Thus, the wavelength of the fastestgrowing mode would be $\sim 750-1000 \mathrm{~m}$. This value is consistent with the interval between adjacent TLVs, which is roughly estimated as $\sim 1000 \mathrm{~m}$ from the simulated sea level pressure distribution (Fig. 7a). Thus, it is

(a) Rain water \& SLP 0441 JST

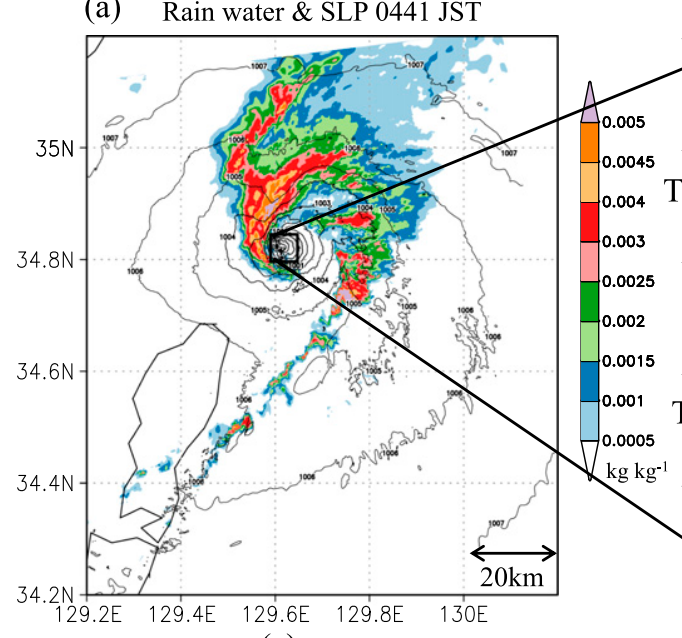

(c)

(b) Vorticity \& SLP \& wind vectors 0441 JST

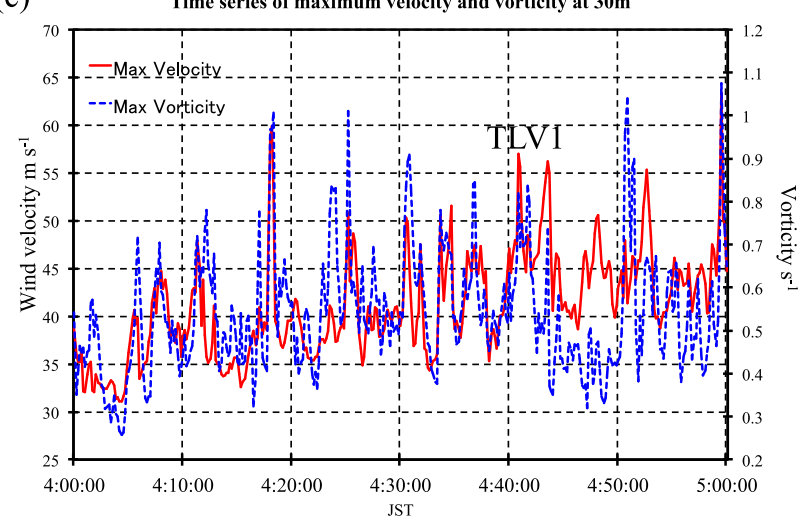

FIG. 6. Simulated characteristics of the meso- $\beta$ vortex on 1 Sep 2015. (a) Simulated rainwater mixing ratio (color shading; $\mathrm{kg} \mathrm{kg}^{-1}$ ) and sea level pressure (SLP; bold lines; hPa) at 0441 JST from NHMS50m, and (b) expanded view of simulated vertical vorticity (color shading; $\mathrm{s}^{-1}$ ) at $30-\mathrm{m}$ height, SLP, and horizontal wind vectors for the area indicated by the square in (a). (c) Time sequence of simulated maximum vorticity (blue dashed line; $\mathrm{s}^{-1}$ ) and velocity (red line; $\mathrm{m} \mathrm{s}^{-1}$ ) at 30-m height. 
(a)

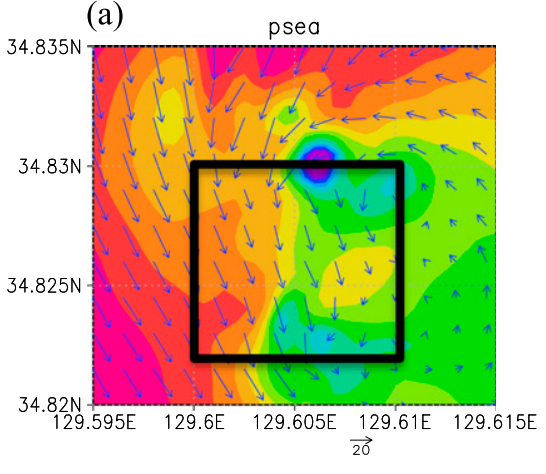

(b)

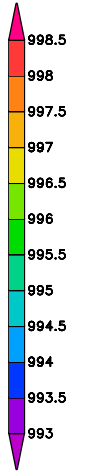

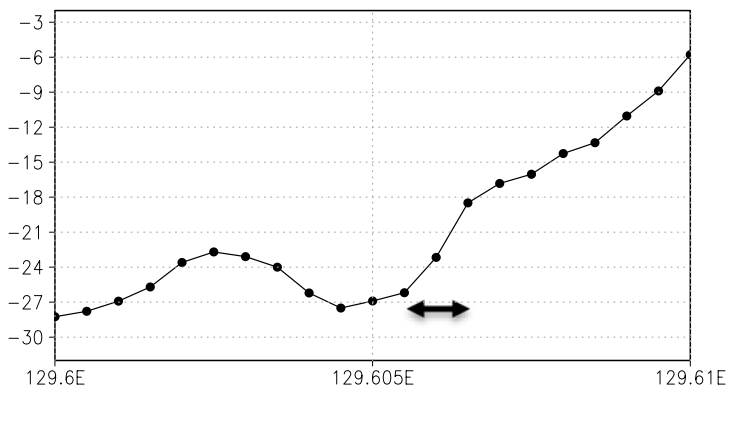

FIG. 7. (a) Horizontal distribution of sea level pressure and wind fields at $30 \mathrm{~m}$ AGL at $0440 \mathrm{JST}$ from NHMS50m. (b) Zonal profile of meridionally-averaged meridional wind at $30 \mathrm{~m}$ AGL.

likely that these vortices are generated and strengthened by a shear instability. Furthermore, it is speculated that the tornado-like vortices are intensified through stretching due to strong updrafts associated with the MBV. Thus, formation process of the tornadolike vortices may be somewhat similar to that of nonsupercell tornadoes (Wakimoto and Wilson 1989) except for the presence of the MBV. The simulated vorticity and wind velocity maxima of the tornado-like vortices near the surface occasionally exceed $1 \mathrm{~s}^{-1}$ and $55 \mathrm{~m} \mathrm{~s}^{-1}$, respectively (Fig. 6c). This wind speed is comparable to category 2 of the Japanese enhanced Fujita (JEF) scale (Tamura et al. 2016). Since gusty winds in the simulated MBV are all associated with tornado-like vortices and are not associated with other types of disturbances, the fishing boats in the Tsushima Strait were possibly capsized by these tornado-like vortices.

\section{b. Formation and development processes of meso- $\beta$-scale vortex}

To understand the formation and development processes of the MBV, the detailed time evolution of the MBV is examined using NHMF2km. Figures $8 \mathrm{a}$ and $8 \mathrm{~b}$ show the maxima of updraft and vorticity, which are sought within a $30 \mathrm{~km} \times 30 \mathrm{~km}$ box around the MBV (a) Time series of Wmax

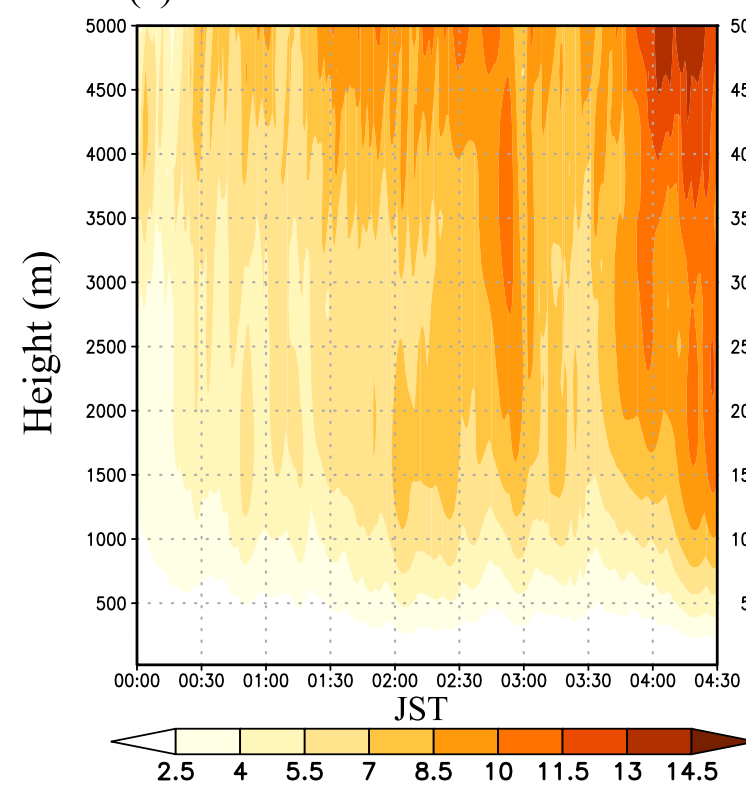

(b) Time series of Vormax

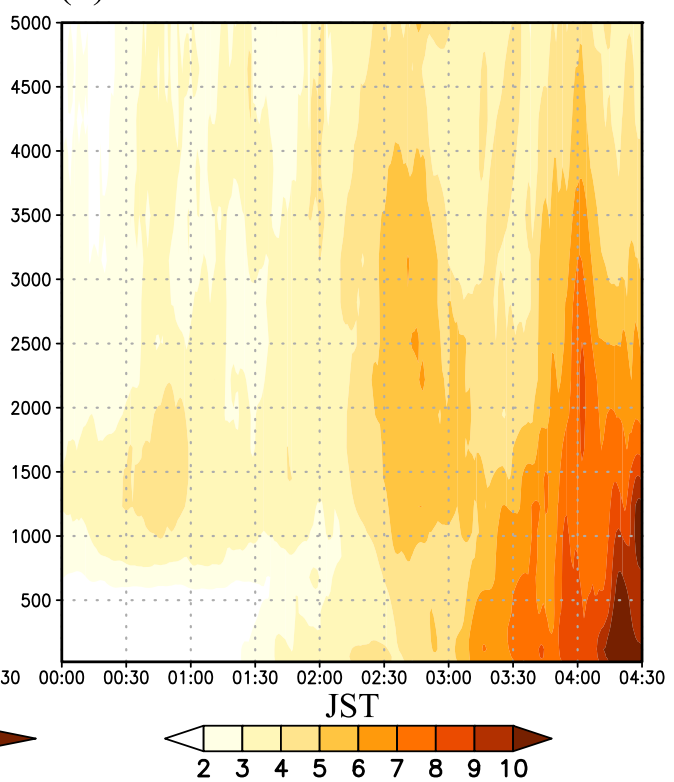

FIG. 8. Time-height cross sections of (a) maximum updraft $\left(\mathrm{m} \mathrm{s}^{-1}\right)$ and (b) maximum vorticity $\left(10^{-3} \mathrm{~s}^{-1}\right)$ from NHMF2km. 
(a) Skew-T at $0100 \mathrm{JST}$

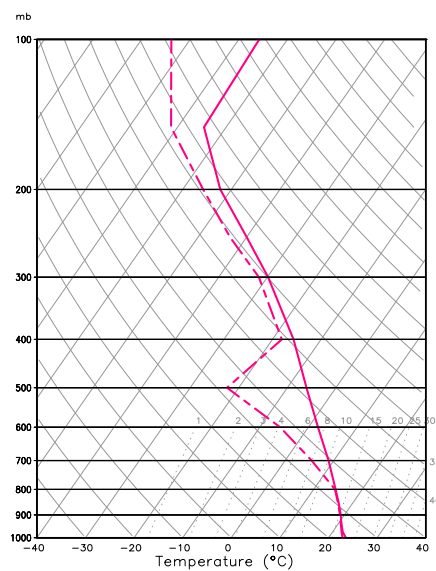

(b) Skew-T at $0330 \mathrm{JST}$

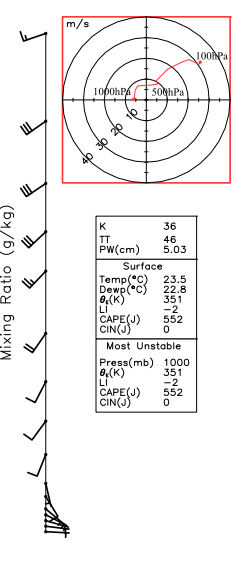

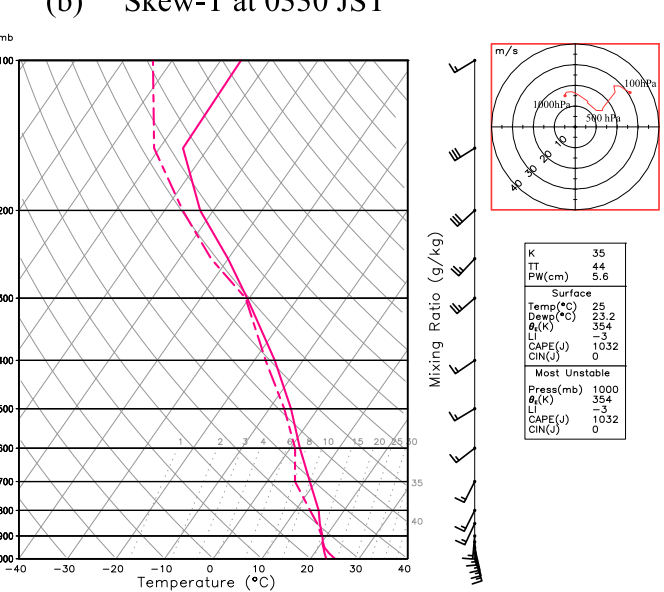

FIG. 9. Skew $T-\log p$ diagram and hodograph in the inflow region at (a) $0100 \mathrm{JST}$ at $34.5^{\circ} \mathrm{N}, 130^{\circ} \mathrm{E}$, and (b) at 0330 JST at $34.65^{\circ} \mathrm{N}, 130.15^{\circ} \mathrm{E}$ from NHMF2 km. Bold lines and dashed lines indicate temperature and dewpoint temperature, respectively.

center. Note that the center of the MBV is defined as the position of the maximum of the vertical vorticity smoothed out over $10 \mathrm{~km} \times 10 \mathrm{~km}$ square at each output time step at $500 \mathrm{~m}$ AGL. The maxima of vorticity and updraft above $1 \mathrm{~km}$ AGL started to intensify at around 0200 JST (Figs. 8a and 8b). Nearsurface vorticity below $100 \mathrm{~m}$ AGL then rapidly intensified from 0330 JST and eventually exceeded $0.01 \mathrm{~s}^{-1}$ at $0420 \mathrm{JST}$. This evolution of vorticity and updraft from 0030 to 0300 JST suggests that the upward pressure gradient force that results from the pressure anomaly cyclostrophically balanced with the strong rotation above $1 \mathrm{~km}$ strengthened the updrafts, and thus contributed to the intensification of the nearsurface vorticity through stretching (not shown). The vertical vorticity of the MBV was strongest near the surface between 0330 and 0430 JST, which is clearly different from supercells that have the maximum mesocyclone vorticity above $1 \mathrm{~km}$ AGL. The mesocyclones around $1 \mathrm{~km}$ AGL in a supercell storm are known to induce strong low-level updrafts and contribute to the tornadogenesis (e.g., Wicker and Wilhelmson 1995; Noda and Niino 2010). However, the low-level updraft in the MBV is at most $10 \mathrm{~m} \mathrm{~s}^{-1}$ at $1 \mathrm{~km}$ AGL, which is much weaker than that in the supercells, suggesting that the formation of TLVs in the MBV is not similar to that in a supercell storm. Near the surface of the MBV, warm and moist air continued to be transported from the southeast during its developing period between 0100 and 0430 JST, and contributed to the maintenance of convection in the EC. The thermodynamic environment for the MBV is close to moist neutral (Fig. 9), while that for MCVs associated with MCSs in the United States (Trier and
Davis 2002; Davis et al. 2004; Davis and Galarneau 2009; Conzemius et al. 2007) is moist neutral or somewhat more unstable. As for the environmental wind, vertical shear in the MBV appears to be comparable or weaker than that in the MCVs: the vertical shear in the MBV is $\sim 10 \mathrm{~m} \mathrm{~s}^{-1}$ over the lowest $3 \mathrm{~km}$ above AGL, which is similar to cases of MCVs with modest vertical shear (e.g., Menard and Fritsch 1989; Davis and Galarneau 2009). In summary, the environment of the MBV is somewhat similar to that of the MCVs. It is noted that vertical shear in the lowest $1 \mathrm{~km}$ above AGL in the present study is $\sim 5-7 \mathrm{~m} \mathrm{~s}^{-1}$, which tends to be weaker than that associated with significant tornadoes (F2 or stronger in the United States; Craven and Brooks 2004).

Time evolution of low-level wind, equivalent potential temperature, and sea level pressure shows that the center of EC is located to the west of the Kyushu Islands $\left(33.5^{\circ} \mathrm{N}, 128.5^{\circ} \mathrm{E}\right.$; Fig. $\left.10 \mathrm{a}\right)$ at $0000 \mathrm{JST}$. In the northeast of the EC center, there is a warm frontal region in which cyclonic horizontal shear between southeasterly and northeasterly winds is remarkable and horizontal gradient of equivalent potential temperature is large $\left(34^{\circ}-35^{\circ} \mathrm{N}, 129^{\circ}-131^{\circ} \mathrm{E}\right)$. As the time elapses, the horizontal shear as well as the horizontal gradient of equivalent potential temperature intensified (Figs. 10b-d).

The horizontal and vertical structures of the rainwater mixing ratio, potential temperature, and wind fields around the convection system related to the MBV at 0130 JST are shown in Fig. 11. Before the intensification of the near-surface vorticity (0030-0330 JST), active convection developed in the region of strong horizontal shear near the surface in the EC (around $34.4^{\circ}-35^{\circ} \mathrm{N}$, 

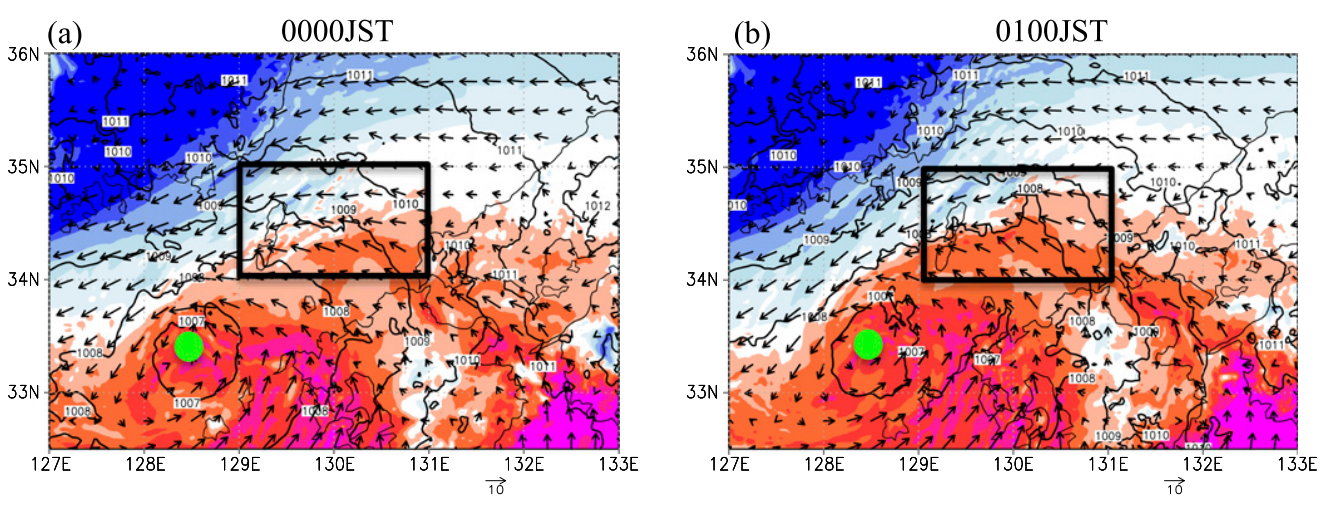

(c)
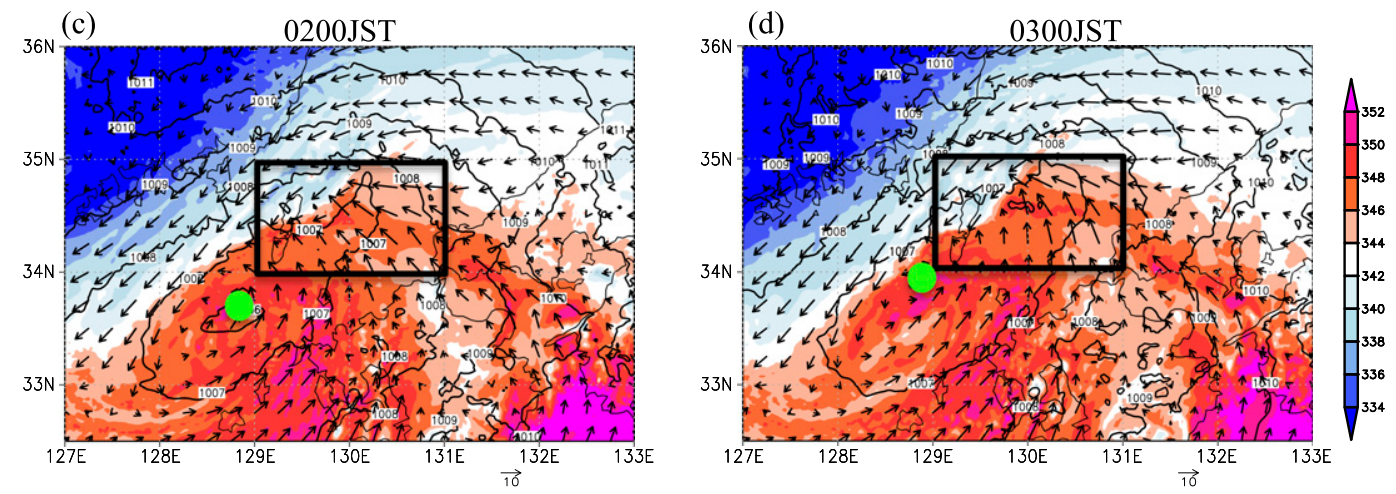

FIG. 10. Horizontal distribution of equivalent potential temperature (color shading; K), sea level pressure (contour lines; hPa), and horizontal wind vectors $\left(\mathrm{m} \mathrm{s}^{-1}\right.$ ) at $530 \mathrm{~m} \mathrm{AGL} \mathrm{at} \mathrm{(a)} 0000 \mathrm{JST}$, (b) $0100 \mathrm{JST}$, (c) $0200 \mathrm{JST}$, and (d) 0300 JST from NHMF2km. Green circles indicate the positions of EC center. Black boxes indicate the region in which horizontal shear and horizontal gradient of equivalent potential temperature are large.

$129.75^{\circ}-130^{\circ} \mathrm{E}$ in Fig. 11a). The region of strong horizontal shear was formed between northeasterly winds to the northwest and southeasterly winds to the southeast of the active convection region (Figs. 11a and 11b). The horizontal shear was strengthened as the convection intensified (Fig. 10). Note that horizontal potential temperature gradient is notably weak (Fig. 11b) compared to typical QLCSs such as bow echo and derecho, which typically have strong cold pools (e.g., Wakimoto et al. 2006b; Weisman and Davis 1998; Weisman et al. 2013). The vertical cross section along the line $\mathbf{A}-\mathrm{A}^{\prime}$ in Fig. 11a indicates that strong and deep updrafts exist in a region of strong vorticity above $1 \mathrm{~km}$ AGL (Fig. 11c). The wind component normal to the cross section shows a change in sign below $1 \mathrm{~km}$ AGL across the convective region, indicating that horizontal shear is stronger near the surface (Fig. 11c).

Figure 12 gives similar plots to Fig. 11 except for the time of the maximum vorticity (0430 JST). The MBV that developed in this region with the active convection (Figs. 12a and 12b) had a shallow structure (below 3-km height) with its largest vertical vorticity near the surface, and it had a warm-core structure at 0430 JST (Fig. 12c).
Horizontal gradient of low-level potential temperature remains weak at this time (Fig. 12b).

The feature of the MBV that had the largest vorticity near the surface at the time of maximum intensity is different from that of the MCVs having the maximum vorticity in the midtroposphere (Zhang 1992; Fritsch et al. 1994; Trier and Davis 2002; Davis and Trier 2007; Davis et al. 2004; Davis and Galarneau 2009; Conzemius et al. 2007). A mesoscale vortex associated with a derecho on 8 May 2009 in the United States (Weisman et al. 2013) exhibited somewhat similar size and structure to those of the MBV in this study. However, the height of the maximum vorticity of the MBV in this study was below $100 \mathrm{~m}$ AGL and was much lower than that of the mesoscale vortex in the derecho (about 1-2-km height).

\section{c. Vorticity budget analysis}

To examine the contribution of physical processes to the increase of MBV's vorticity, we perform a vorticity budget analysis with the output of NHMF2km (Table 1). The vertical vorticity equation used in this analysis is written as 
(a) Rain water 0130 JST 1 Sep. 2015

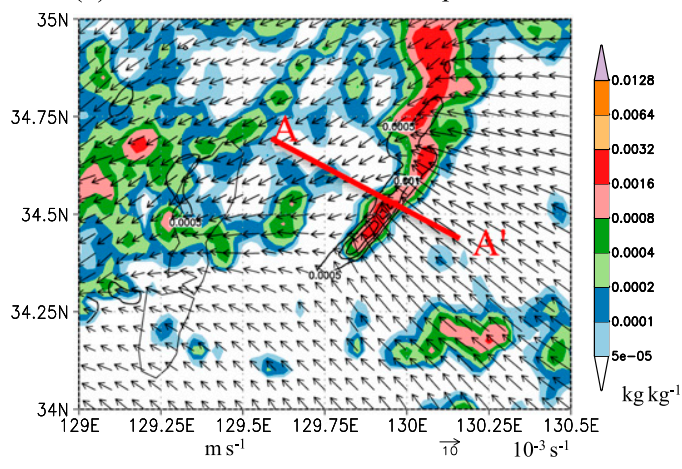

(b) Vertical velocity 0130 JST 1 Sep. 2015

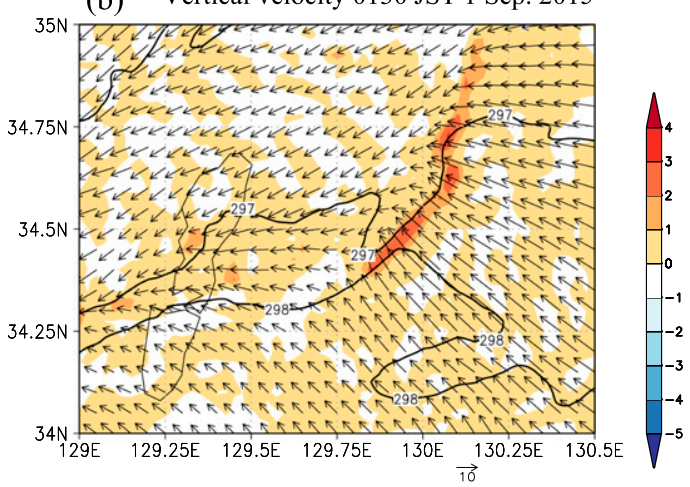

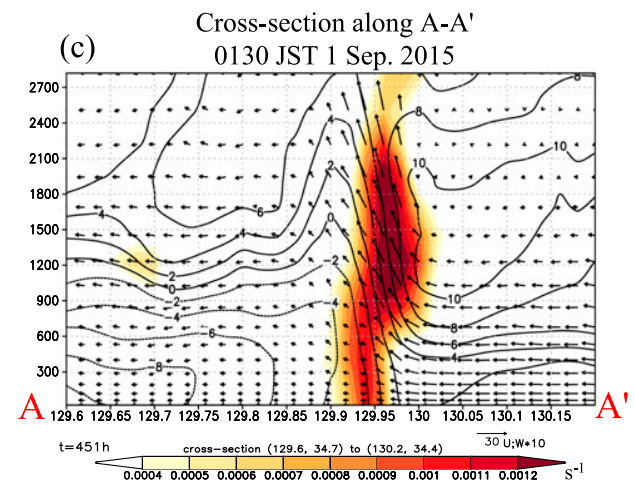

FIG. 11. (a) Horizontal distribution of rainwater mixing ratio (color shading; $\mathrm{kg} \mathrm{kg}^{-1}$ ), vertical vorticity (contour lines; $\mathrm{s}^{-1}$ ), and horizontal wind vectors $\left(\mathrm{m} \mathrm{s}^{-1}\right)$ at $118-\mathrm{m}$ height at $0130 \mathrm{JST}$ from NHMF2km. (b) Horizontal distribution of vertical velocity at $1000-\mathrm{m}$ height (color shading; $\mathrm{m} \mathrm{s}^{-1}$ ), potential temperature at 118-m height (contour lines; K), and horizontal wind vectors $\left(\mathrm{m} \mathrm{s}^{-1}\right)$ at $118-\mathrm{m}$ height at $0130 \mathrm{JST}$ from NHMF2km. (c) Vertical cross section along line $\mathrm{A}-\mathrm{A}^{\prime}$ in (a) where color shading indicates vertical vorticity $\left(\mathrm{s}^{-1}\right)$, bold lines are the wind components normal to the cross section, and arrows are wind vectors parallel to the cross section. The vertical component of the vectors is multiplied by 10 to emphasize the upward motion.

$$
\begin{aligned}
\frac{\partial}{\partial t}(\zeta+f)= & -\left[u \frac{\partial \zeta}{\partial x}-v \frac{\partial(\zeta+f)}{\partial y}\right]-w \frac{\partial \zeta}{\partial z}-(\zeta+f)\left(\frac{\partial u}{\partial x}+\frac{\partial v}{\partial y}\right)+\left(\frac{\partial u}{\partial z} \frac{\partial w}{\partial y}+\frac{\partial v}{\partial z} \frac{\partial w}{\partial x}\right) \\
& +\frac{1}{\rho}\left(\frac{\partial \rho}{\partial x} \frac{\partial p}{\partial y}-\frac{\partial \rho}{\partial y} \frac{\partial p}{\partial x}\right)+\left(\frac{\partial F^{y}}{\partial x}-\frac{\partial F^{x}}{\partial y}\right)
\end{aligned}
$$

where $\zeta$ is the vertical component of relative vorticity, $f$ is the vertical component of planetary vorticity, $u$ is the zonal velocity, $v$ is the meridional velocity, $w$ is the vertical velocity, and $\mathbf{F} \equiv\left(F^{x}, F^{y}\right)$ is the horizontal friction vector. The first term on the right-hand side (rhs) of Eq. (1) is the horizontal advection term, the second is the vertical advection term, the third is the stretching term, the fourth is the tilting term, the fifth is the solenoidal term, and the sixth is the friction term. The friction term is calculated from the turbulent viscosity terms in the momentum equation.

To perform the vorticity budget analysis, we first determine the center of the MBV. The vertical vorticity is smoothed onto grid points of $10 \mathrm{~km}$ from output data at 20-min intervals $(0000,0020$, and 0040 JST), and the center of the MBV is then defined as the maximum of the smoothed vertical vorticity at 500-m height. In the calculation of horizontal advection terms, translation speed, which is estimated by the movement of the MBV center, is subtracted from horizontal winds. The box for calculation of each term of the vorticity equation in Eq. (1) is made for a horizontal box of $60 \mathrm{~km} \times 60 \mathrm{~km}$. Each term is calculated using these output data at 1-min interval, where the positions of the MBV center at 1-min intervals are calculated by linearly interpolating those at 20-min intervals. To improve the calculation accuracy of the vorticity budget, we adopt the ensemble approach of Davis and Galarneau (2009). At each output of 1-min intervals, the box is perturbed from its central 
(a) Rain water 0430 JST 1 Sep. 2015

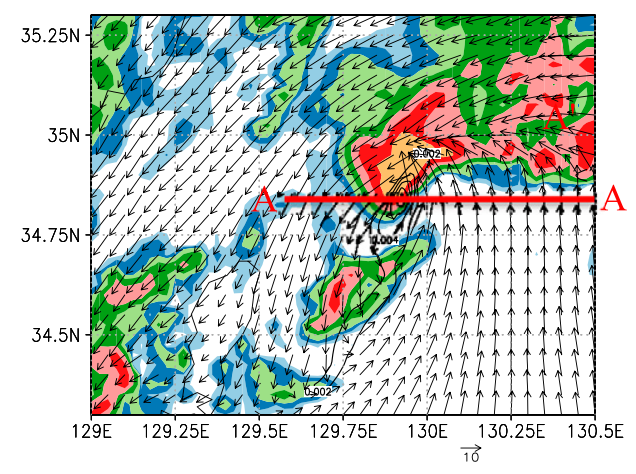

(b) Vertical velocity 0430 JST 1 Sep. 2015

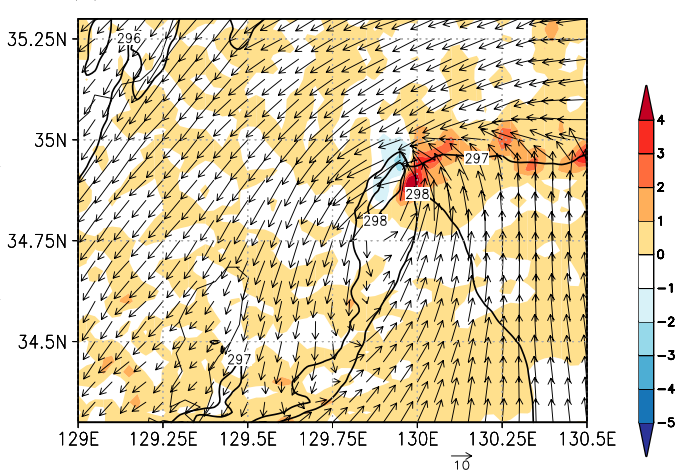

(c)

Zonal-vertical cross section 0430 JST 1 Sep. 2015

A

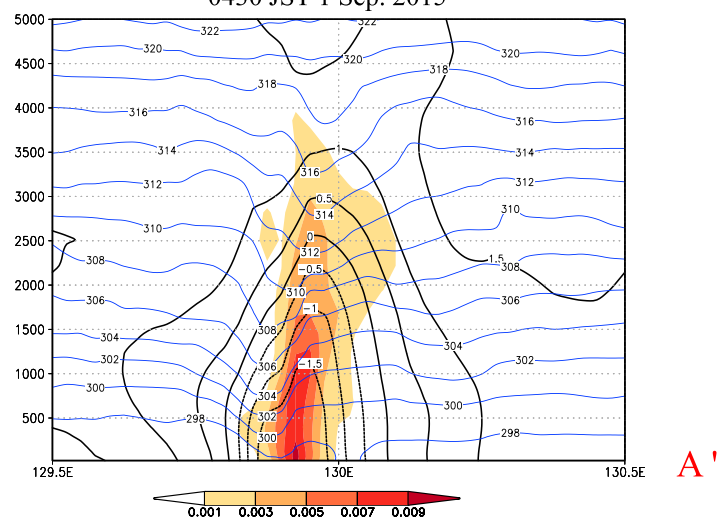

FIG. 12. (a) Horizontal distribution of rainwater mixing ratio (color shading; $\mathrm{kg} \mathrm{kg}^{-1}$ ), vertical vorticity (contour lines; $\mathrm{s}^{-1}$ ), and horizontal total wind vectors $\left(\mathrm{m} \mathrm{s}^{-1}\right)$ at $118-\mathrm{m}$ height at $0420 \mathrm{JST}$ from NHMF2km. (b) Horizontal distribution of vertical velocity at $1000-\mathrm{m}$ height (color shading; $\mathrm{m} \mathrm{s}^{-1}$ ), potential temperature at 118-m height (contour lines; K), and horizontal wind vectors $\left(\mathrm{m} \mathrm{s}^{-1}\right)$ at $118-\mathrm{m}$ height at $0130 \mathrm{JST}$ from NHMF2km. (c) Longitude-height cross section through the MBV center at 0430 JST [A-A' line in (a)], where vertical vorticity is shown by color shading $\left(\mathrm{s}^{-1}\right)$, pressure anomaly by black solid lines $(\mathrm{hPa})$, and potential temperature $(\mathrm{K})$ by blue solid lines. Note that pressure anomalies are calculated as deviations from area-averaged pressure at each height.

location \pm 5 grid points $( \pm 10 \mathrm{~km})$ in both $x$ and $y$ directions. Thus, vorticity budget is calculated for $11 \times 11$ boxes. All of terms of vorticity budget and local tendency of the vorticity are averaged over 121 boxes. Although there are some differences between local tendency of the vorticity and a sum of all terms in the rhs of Eq. (1), the intensification of vorticity at midlevels at the early developing stage and that at the near surface at a later developing stage are reasonably captured in the present analysis (Fig. 13).

Figure 14 shows time evolution of each term in the vorticity budget equation [Eq. (1)]. At the formation and early developing stages of the MBV (0130-0330 JST), positive contributions of tilting and stretching terms are found at $500-1500-\mathrm{m}$ height. The stretching term also has a positive contribution at lower levels (between $500 \mathrm{~m}$ and near the surface). Above $1500 \mathrm{~m}$, on the other hand, both tilting and stretching terms have negative or slightly positive values in this period. Horizontal and vertical advection terms are generally negative below 1500-m height, while positive above 1500-m height. The values of solenoidal term are quite small through the developing stage. Thus, the MBV formed and developed through the tilting of horizontal vorticity and stretching of vertical vorticity at the early developing stage (0130-0330 JST). Figure 15a shows normalized inner products of horizontal vorticity and horizontal velocity vectors at 0130 JST. Horizontal vorticity vectors are nearly parallel to horizontal velocity vectors in the inflow region of the convective system. Figure $15 \mathrm{~b}$ shows a normalized inner product of vorticity and velocity vectors (normalized helicity) in the vertical cross section along the line $\mathrm{A}-\mathrm{A}^{\prime}$ in Fig. 15a. It is seen that the inflow having large normalized helicity turns vertically in the updraft region and causes large vertical vorticity. Thus, it is suggested that the vertical vorticity at $700-\mathrm{m}$ height is caused by the 


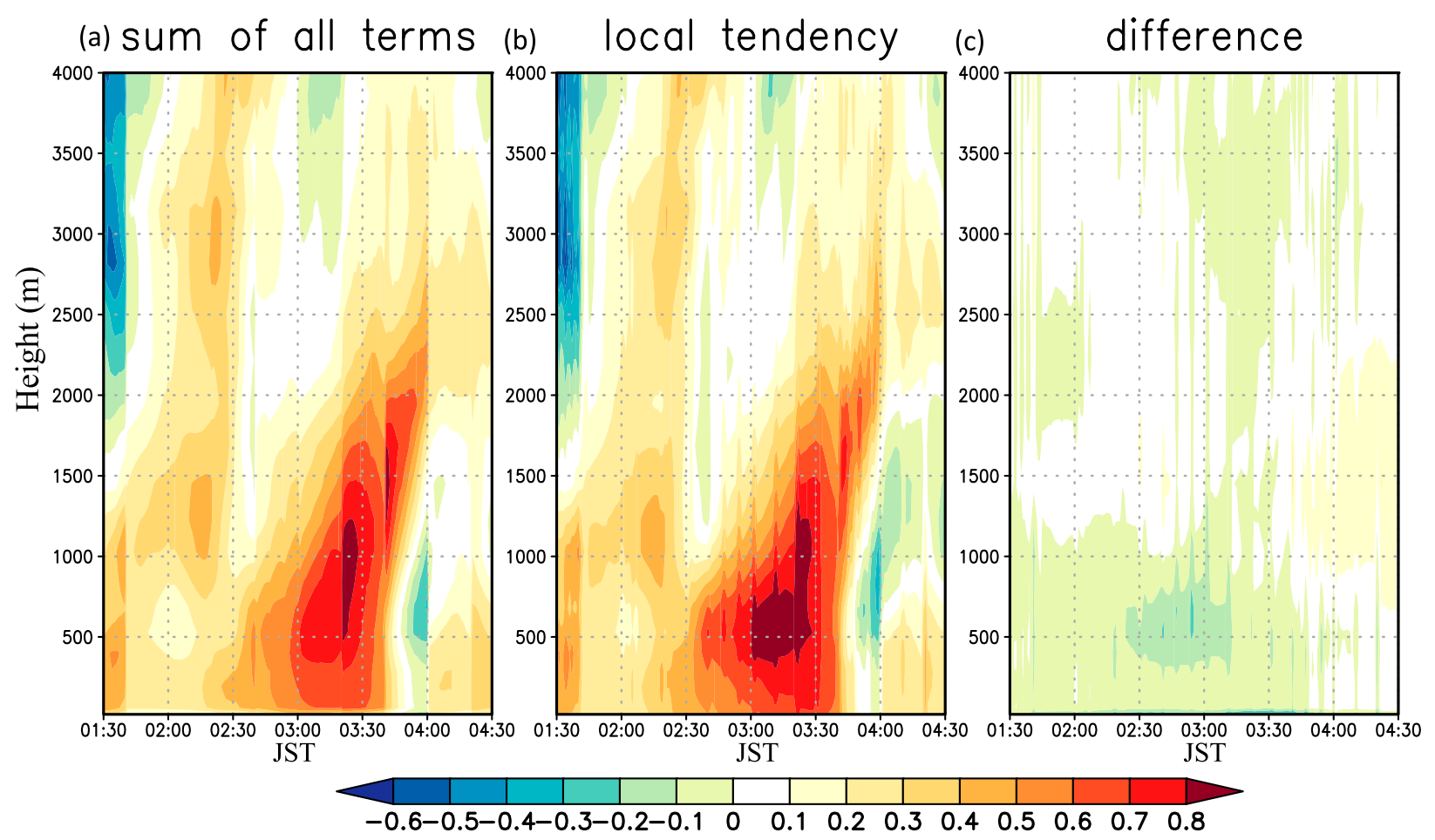

FIG. 13. Time-height diagrams of (a) sum of all vorticity budget terms, (b) local tendency of vertical vorticity, and (c) difference between (a) and (b) from NHMF2km. The vorticity first intensified about 1-km height, and then below 500-m height.

tilting of horizontal vorticity, which originates from the vertical shear of winds field associated with the EC (not shown). At the later developing stage (0330-0430 JST), the contribution of the stretching dominates near the surface, while the tilting is negative or slightly positive. The other terms, such as horizontal and vertical advection, and solenoidal terms, indicate negative or slightly positive contributions. Thus, the MBV at the later stage develops through the stretching of vertical vorticity near the surface.

\section{d. Circulation analysis}

To quantitatively clarify the origin of the near-surface strong vorticity developed at the later developing stage, we perform a circulation analysis. Since the circulation analysis requires a velocity field with fine spatiotemporal resolution to reduce numerical errors (Dahl et al. 2012), we use the results of NHMF350m (Table 1). The circulation $C$ can be written as

$$
C=\oint \mathbf{v} \cdot \mathbf{d} \mathbf{l}
$$

where $\mathbf{v}$ is the wind vector and $\mathbf{d l}$ is the displacement vector tangent to a circuit. From Stokes's theorem, the circulation corresponds to the areal integration of the vorticity. The circulation analysis adopted here is similar to that of previous studies (Markowski and Richardson 2014; Mashiko 2016a, b). Initially, 900 parcels were placed along a circuit surrounding the strong vorticity (Fig. 16a), which was associated with the MBV, and were integrated backward in time. If adjacent parcels on the circuit were more than $350 \mathrm{~m}$ apart, we added a parcel on the circuit at the midpoint between the two adjacent parcels. The backward trajectory was calculated using a fourth-order Runge-Kutta scheme with a time step of $1 \mathrm{~s}$. The wind fields at each parcel location were obtained from 10-s model outputs. A logarithmic wind profile is assumed at the heights below the lowest model level at $z^{*}=20 \mathrm{~m}$. The time rate of change of the circulation can be written as

$$
\frac{d}{d t} C(t)=-\oint \frac{d p}{\rho}+\oint \mathbf{F} \cdot \mathbf{d} \mathbf{l}
$$

where $\rho$ is density, $p$ is pressure, $\mathbf{F}$ is friction vector, and the first term on the rhs is the baroclinic term. In the present study, the value of $\mathbf{F}$ below the lowest model height was assumed to have the same value as that at the lowest model level. The effects of these two terms were directly calculated using 10 -s output. The evolution of the circulation calculated directly is compared with that calculated by integrating the sum of the rhs of Eq. (3). 
Time evolutions of each tendency term at each level
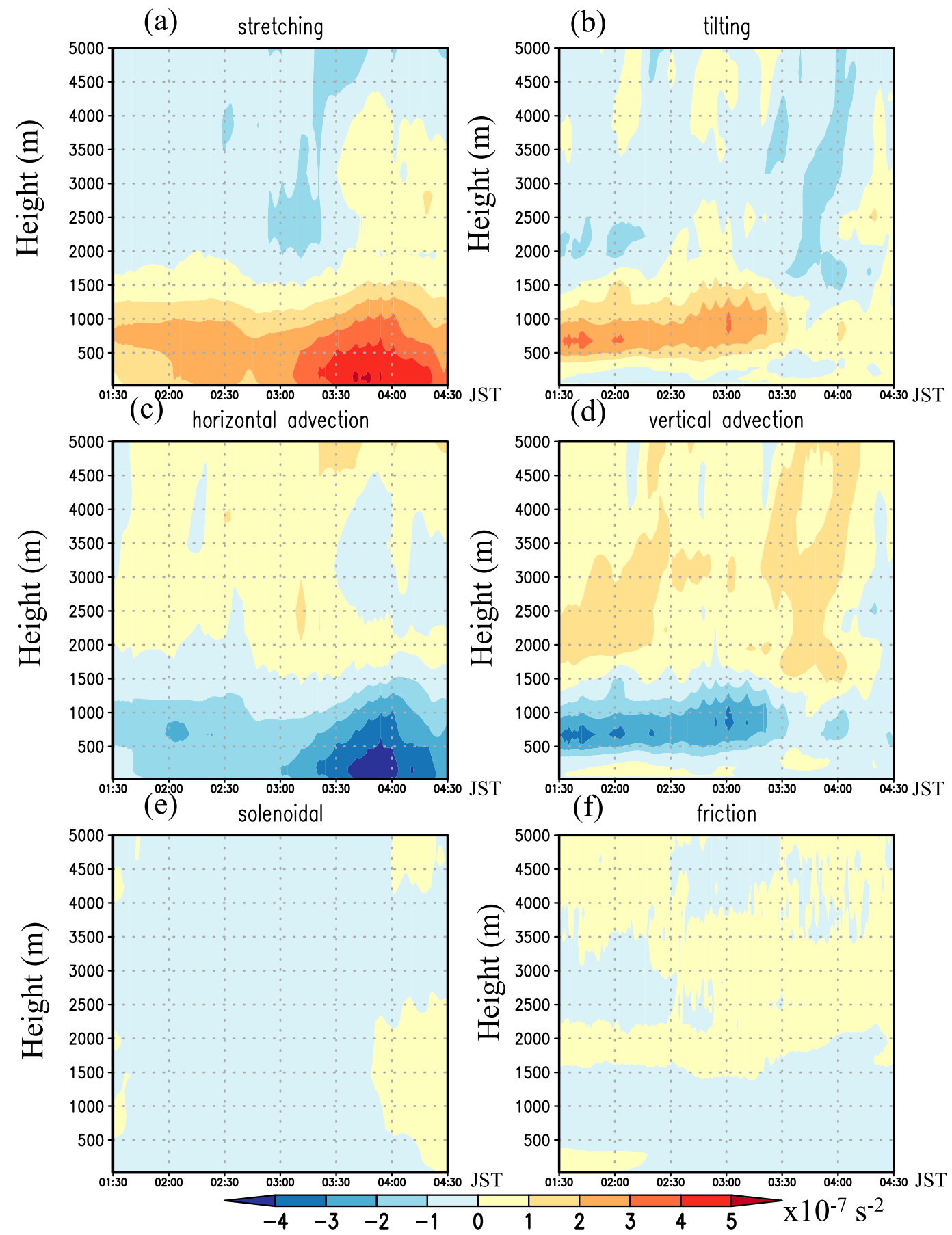

FIG. 14. Time-height diagrams of vorticity budget terms from NHMF2km: (a) stretching, (b) tilting, (c) horizontal advection, (d) vertical advection, (e) solenoidal, and (f) friction.

The evolution of circulation and the contributions of baroclinicity and friction to the tendency of the circulation are shown in Fig. 16b. Although the circulation of $\sim 100000 \mathrm{~m}^{2} \mathrm{~s}^{-1}$ at $0345 \mathrm{JST}$ decreased to $80000 \mathrm{~m}^{2} \mathrm{~s}^{-1}$ at 0408 JST, its value remained large (Fig. 16b), indicating that the circulation of the MBV originated from the environmental wind fields surrounding the MBV. The decrease in the circulation is caused by the net effect 
(a)

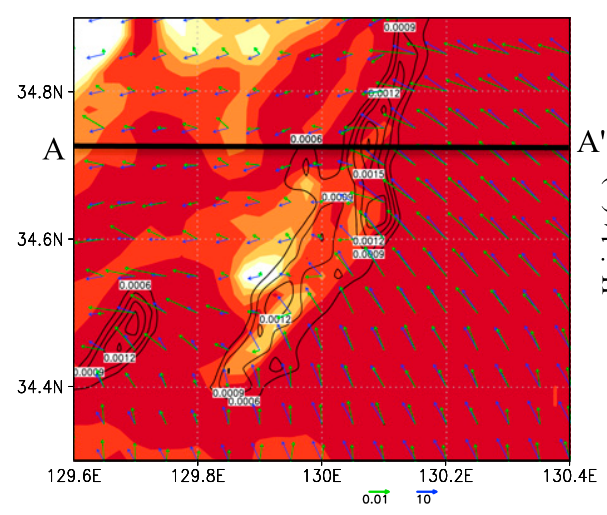

(b)

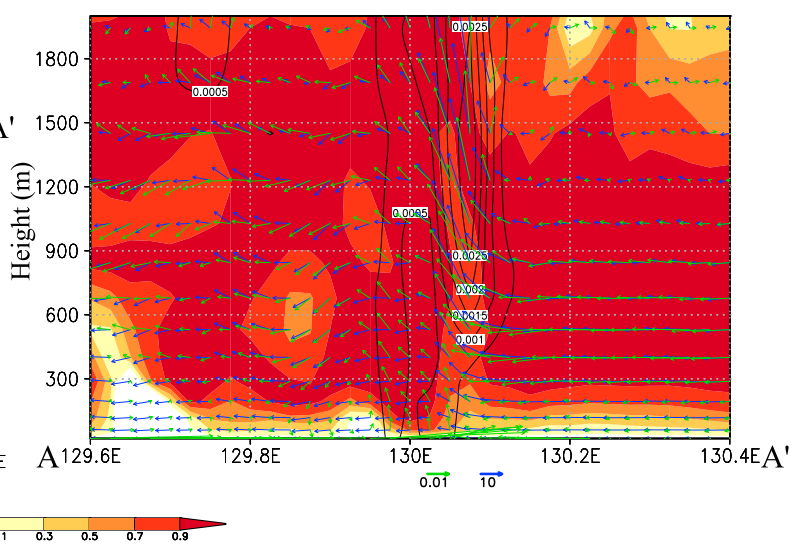

FIG. 15. (a) Normalized inner products of horizontal vorticity vector and horizontal velocity vector (color shading) at 700-m height at 0130 JST from NHMF2 km. Blue and yellow green arrows indicate horizontal velocity vectors $\left(\mathrm{m} \mathrm{s}^{-1}\right)$ and horizontal vorticity $\left(\mathrm{s}^{-1}\right)$ vectors, respectively. (b) Vertical cross section along line $\mathrm{A}-\mathrm{A}^{\prime}$ in (a), where color shading indicates normalized inner product of vorticity vector and velocity vector (normalized helicity). Blue and yellow green arrows indicate vorticity and velocity vectors, respectively, parallel to the cross section. Note that the vertical components of the vectors in (a) are multiplied by 10 to emphasize the vertical vorticities and velocities. Black contour lines in (a) and (b) indicate vertical vorticity $\left(\mathrm{s}^{-1}\right)$.

of the friction term, while the net effect of baroclinicity is negligibly small.

To understand how the wind fields around the MBV contribute to the circulation at 0408 JST, we examine the details of the circuit near the surface at 0345 JST (Figs. 16c-e). The circuit is now composed of 1500 parcels, most of which are located below $20 \mathrm{~m}$. The circuit extends to the northeast, east, and southeast from the region of strong vorticity near the surface. Figure $16 \mathrm{c}$ shows the horizontal distribution of wind fields at $20-\mathrm{m}$ height at 0345 JST. The parts of the circuit extending to the northeast, east, and southeast are associated with northeasterly, easterly, and southeasterly winds, respectively. To clarify the quantitative contributions of the five subcircuits C1-C5 (Fig. 16d) to the total circulation, we calculate the circulation along each subcircuit (Fig. 16e). The largest contribution to the total circulation, $75693 \mathrm{~m}^{2} \mathrm{~s}^{-1}$, is from $\mathrm{C} 2$. The second largest contribution, $35343 \mathrm{~m}^{2} \mathrm{~s}^{-1}$, is from $\mathrm{C} 3$. The northeasterly and southeasterly winds are the dominant contributors to the positive values of $\mathrm{C} 2$ and $\mathrm{C} 3$, respectively. $\mathrm{C} 4$ also has a positive value due to the easterly winds, while $\mathrm{C} 1$ and C5 have negative and small positive values, respectively. These results reveal that the near-surface strong circulation originated from the vertical vorticity induced by the horizontal shear between northeasterly, easterly, and southeasterly winds in the EC. This shear was intensified by the convergence of the convective system associated with the MBV (Figs. 10 and 11a). This formation mechanism of the MBV differs from that of the mesovortices associated with QLCSs in which friction and baroclinity play significant roles (Atkins and St. Laurent 2009; Xu et al. 2015).

We also have calculated forward trajectories of the air parcels located at the final positions of the backward trajectories. The forward trajectory analysis have shown that the circulation along the circuit enclosing locations of forward-integrated trajectories at 0408 JST is about $82000 \mathrm{~m}^{2} \mathrm{~s}^{-2}$, which is close to $83000 \mathrm{~m}^{2} \mathrm{~s}^{-2}$ along the circuit enclosing initial locations of backward trajectories. In addition, the final locations of forwardintegrated trajectories are very close to the initial locations of backward trajectories (not shown).

\section{Discussion and summary}

The present high-resolution numerical simulation has demonstrated that the sinking of boats in the Tsushima Strait on 1 September 2015 is likely to have been caused by a hierarchy of multiscale atmospheric disturbances ranging from the weak $\mathrm{EC}(\sim 1000 \mathrm{~km})$ through the MBV $(\sim 30 \mathrm{~km})$ to the tornado-like vortices $(\sim 100 \mathrm{~m})$. The simulation suggests that the tornado-like vortices had a horizontal velocity of up to $55 \mathrm{~m} \mathrm{~s}^{-1}$. The MBV, which has a unique structure with the largest vertical vorticity near the surface and generated the tornado-like vortices, is shown to have been caused by horizontal convergence due to the active convective system and horizontal shear in the EC. On the other hand, it is speculated that tornado-like vortices are likely to have been generated by the instability of horizontal shear in the western part of the MBV together with updrafts in the MBV. 


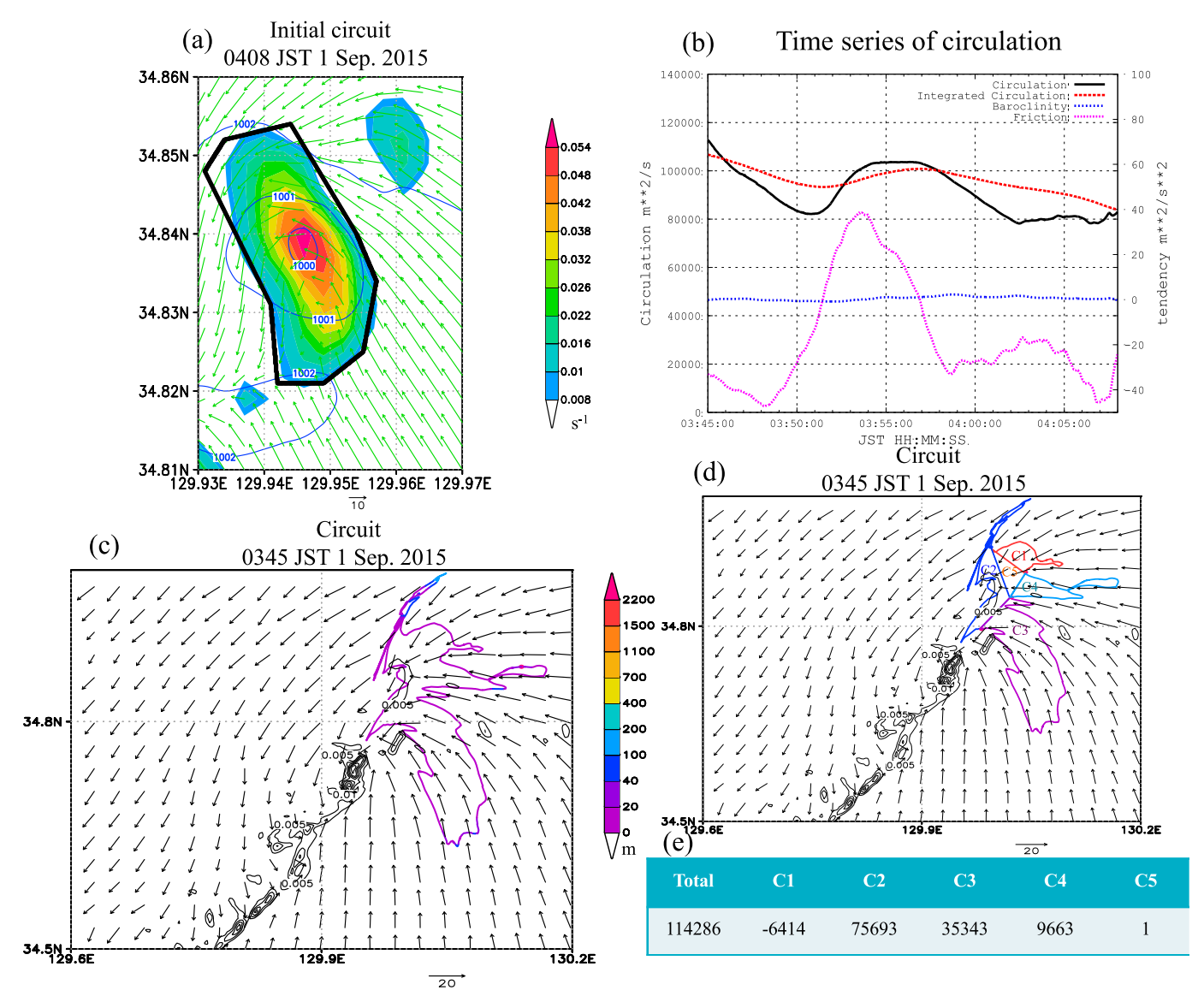

FIG. 16. Backward trajectory analysis for examining the origin of strong vertical vorticity of the meso- $\beta$ vortex from NHMF350m. (a) Vertical vorticity (color shading) and pressure (blue contour lines; hPa) at $60 \mathrm{~m}$ at 0408 JST and the initial position of the material circuit (thick black line). (b) Time evolution of circulation (black line; $\mathrm{m}^{2} \mathrm{~s}^{-1}$ ) together with that of baroclinic (blue dotted line; $\mathrm{m}^{2} \mathrm{~s}^{-2}$ ) and frictional (purple dotted line; $\mathrm{m}^{2} \mathrm{~s}^{-2}$ ) terms, where the red dotted line indicates the integrated circulation $\left(\mathrm{m}^{2} \mathrm{~s}^{-1}\right)$ calculated by time-integrating the sum of the baroclinic and frictional terms. (c) Horizontal projection of the circuit at 0345 JST. The color scale indicates the height of the circuit. (d) Decomposition of the circuit into subcircuits C1 (red), C2 (blue), C3 (purple), C4 (bright blue), and C5 (orange), where solid black lines and wind vectors in (c) and (d) indicate vertical vorticity $\left(\mathrm{s}^{-1}\right)$ and horizontal wind $\left(\mathrm{m} \mathrm{s}^{-1}\right)$ at 20-m height, respectively. (e) Contributions of C1-C5 to the total circulation $\left(\mathrm{m}^{2} \mathrm{~s}^{-1}\right)$.

The size, structure, and formation mechanism of the MBV are somewhat different from those of MCVs and mesovortices, which are observed within MCSs in the United States. The vertical vorticity of the MCVs are generated mainly through tilting of the horizontal vorticity in the environmental wind or stretching of planetary and relative vorticity and often has a maximum at the midtroposphere, but that of the MBV is enhanced by stretching of the vertical vorticity in the near-surface horizontal shear and is largest near the surface. The size of the MBV is smaller than a typical horizontal scale of MCVs (100-300 km; Davis and Galarneau 2009) and is larger than that of mesovortices $(5-20 \mathrm{~km})$, which often occur at the leading edge of a QLCS (Schenkman et al. 2012) or a bow echo. Line-end vortices forming within bow-echo have the size of $10-100 \mathrm{~km}$, which is similar to the MBV. However, the line-end vortices are usually strongest at $2-4-\mathrm{km}$ height and their vertical vorticity are thought to originate from buoyantly (baroclinically) generated horizontal vorticity (e.g., Weisman and Davis 1998). Furthermore, the MBV is not associated with preexisting MCCs (Figs. 2 and 3).

A similar MBV, which has the structure with the largest vertical vorticity near the surface and is accompanied by a spiral-shaped precipitation system, embedded in a weak EC in the northeast part of the East China Sea was also observed on 21 August 2011 and resulted in the capsizing of a fishing vessel. Furthermore, two cases of similar MBVs have been observed over the Pacific Ocean near the south coast of the Japanese islands on 22 September and 17 October 2016, although no shipwrecks were reported for these cases. Thus, this type of MBV and the 
associated tornado-like vortices are a potential risk to maritime traffic, meaning that it is important to accumulate similar case studies and understand the environmental conditions that lead to their generation. Moreover, ensemble experiments and associated ensemble sensitivity analysis as was made by Yokota et al. (2018) may be useful to examine what structures of MBVs are favorable to cause tornado-like vortices.

Acknowledgments. This work was supported by JSPS KAKENHI Grants 18H01277 and 17K14391, and FLAGSHIP2020 of Ministry of Education, Culture, Sports, and Technology within the priority study Advancement of Meteorological and Global Environmental Predictions Utilizing Observational "Big Data." This research used computational resources of the $\mathrm{K}$ computer provided by the RIKEN Advanced Institute for Computational Science (currently Center for Computational Science) through the HPCI System Research project (Project ID: hp160229, hp170246, hp180194). We are also grateful to Prof. C. Weiss and two anonymous reviewers for their constructive comments and suggestions that improved the manuscript. The dataset of the Fukuoka radar is provided by JMA. Since the code of the JMA Nonhydrostatic model and Doppler radar data are owned by JMA, we need to ask JMA for permission on the basis of individual request.

\section{REFERENCES}

American Meteorological Society, 2015: "Line-end vortices." Glossary of Meteorology, http://glossary.ametsoc.org/wiki/ Line-end_vortices.

Atkins, N. T., and M. St. Laurent, 2009: Bow echo mesovortices. Part II: Their genesis. Mon. Wea. Rev., 137, 1514-1532, https:// doi.org/10.1175/2008MWR2650.1.

—, J. M. Arnott, R. W. Przybylinski, R. A. Wolf, and B. D. Ketcham, 2004: Vortex structure and evolution within bow echoes. Part I: Single-Doppler and damage analysis of the 29 June 1998 derecho. Mon. Wea. Rev., 132, 2224-2242, https://doi.org/ 10.1175/1520-0493(2004)132<2224:VSAEWB > 2.0.CO;2.

- C. S. Bouchard, R. W. Przybylinski, R. J. Trapp, and G. Schmocker, 2005: Damaging surface wind mechanisms within the 10 June 2003 Saint Louis bow echo during BAMEX. Mon. Wea. Rev., 133, 2275-2296, https://doi.org/10.1175/ MWR2973.1.

Browning, K. A., 1964: Airflow and precipitation trajectories within severe local storms which travel to the right of the winds. J. Atmos. Sci., 21, 634-639, https://doi.org/10.1175/15200469(1964)021<0634:AAPTWS > 2.0.CO;2.

Conzemius, R. J., R. W. Moore, M. T. Montgomery, and C. A. Davis, 2007: Mesoscale convective vortex formation in a weakly sheared moist neutral environment. J. Atmos. Sci., 64, 1443-1466, https://doi.org/10.1175/JAS3898.1.

Corfidi, S., S. Weiss, J. Kain, S. Corfidi, R. Rabin, and J. Levit, 2010: Revisiting the 3-4 April 1974 Super Outbreak of tornadoes. Wea. Forecasting, 25, 465-510, https://doi.org/10.1175/ 2009WAF2222297.1.
Craven, J. P., and H. E. Brooks, 2004: Baseline climatology of sounding derived parameters associated with deep, moist convection. Natl. Wea. Dig., 28, 13-24.

Dahl, J. M. L., M. D. Parker, and L. J. Wicker, 2012: Uncertainties in trajectory calculations within near-surface mesocyclones of simulated supercells. Mon. Wea. Rev., 140, 2959-2966, https:// doi.org/10.1175/MWR-D-12-00131.1.

Davis, C. A., and S. B. Trier, 2007: Mesoscale convective vortices observed during BAMEX. Part I: Kinematic and thermodynamic structure. Mon. Wea. Rev., 135, 2029-2049, https:// doi.org/10.1175/MWR3398.1.

_ , and T. J. Galarneau, 2009: The vertical structure of mesoscale convective vortices. J. Atmos. Sci., 66, 686-704, https://doi.org/ 10.1175/2008JAS2819.1.

- - and Coauthors, 2004: The bow echo and MCV experiment: Observations and opportunities. Bull. Amer. Meteor. Soc., 85, 1075-1093, https://doi.org/10.1175/BAMS-85-8-1075.

Deardorff, J. W., 1980: Stratocumulus-capped mixed layers derived from a three-dimensional model. Bound.-Layer Meteor., 18, 495-527, https://doi.org/10.1007/BF00119502.

Fritsch, J. M., J. D. Murphy, and J. S. Kain, 1994: Warm core vortex amplification over land. J. Atmos. Sci., 51, 1780-1807, https:// doi.org/10.1175/1520-0469(1994)051<1780:WCVAOL>2.0.CO;2.

Fujita, T. T., 1978: Manual of downburst identification for project Nimrod. Satellite and Mesometeorology Research Paper 156, Dept. of Geophysical Science, University of Chicago, 104 pp. [NTIS-PB-286048]

_ 1979: Objective, operation, and results of Project NIMROD. Preprints, 11th Conf. on Severe Local Storms, Kansas City, MO, Amer. Meteor. Soc., 259-266.

Funk, T., K. Darmofal, J. Kirkpatrick, V. DeWald, R. Przbylinski, G. Schmocker, and Y.-J. Lin, 1999: Storm reflectivity and mesocyclone evolution associated with the 15 April 1994 squall line of Kentucky and southern Indiana. Wea. Forecasting, 14, 976-993, https://doi.org/10.1175/1520-0434(1999) 014<0976:SRAMEA > 2.0.CO;2.

Ikawa, M., H. Mizuno, T. Matsuo, M. Murakami, Y. Yamada, and K. Saito, 1991: Numerical modeling of the convective snow cloud over the Sea of Japan: Precipitation mechanism and sensitivity to ice crystal nucleation rates. J. Meteor. Soc. Japan, 69, 641-667, https://doi.org/10.2151/jmsj1965.69.6_641.

Johns, R. H., and C. A. Doswell, 1992: Severe local storms forecasting. Wea. Forecasting, 7, 588-612, https://doi.org/10.1175/ 1520-0434(1992)007<0588:SLSF>2.0.CO;2.

Klemp, J. B., and R. Rotunno, 1983: A study of the tornadic region within a supercell thunderstorm. J. Atmos. Sci., 40, 359-377, https://doi.org/10.1175/1520-0469(1983)040<0359:ASOTTR $>$ 2.0.CO;2.

Lemon, L. R., and C. A. Doswell III, 1979: Severe thunderstorm evolution and mesocyclone structure as related to tornadogenesis. Mon. Wea. Rev., 107, 1184-1197, https://doi.org/ 10.1175/1520-0493(1979)107<1184:STEAMS>2.0.CO;2.

Maddox, R. A., 1980: Mesoscale convective complexes. Bull. Amer. Meteor. Soc., 61, 1374-1400, https://doi.org/10.1175/ 1520-0477(1980)061<1374:MCC > 2.0.CO;2.

Markowski, P., and Y. Richardson, 2014: The influence of environmental low-level shear and cold pools on tornadogenesis: Insights from idealized simulations. J. Atmos. Sci., 71, 243-275, https://doi.org/10.1175/JAS-D-13-0159.1.

Mashiko, W., 2016a: A numerical study of the 6 May 2012 Tsukuba City Supercell Tornado. Part I: Vorticity sources of low-level and midlevel mesocyclones. Mon. Wea. Rev., 144, 1069-1092, https://doi.org/10.1175/MWR-D-15-0123.1. 
_ 2016b: A numerical study of the 6 May 2012 Tsukuba City Supercell Tornado. Part II: Mechanisms of tornadogenesis. Mon. Wea. Rev., 144, 3077-3098, https://doi.org/10.1175/ MWR-D-15-0122.1.

— , H. Niino, and T. Kato, 2009: Numerical simulation of tornadogenesis in an outer-rainband minisupercell of Typhoon Shanshan on 17 September 2006. Mon. Wea. Rev., 137, 42384260, https://doi.org/10.1175/2009MWR2959.1.

McCaul, E. W., Jr., 1991: Buoyancy and shear characteristics of hurricane-tornado environments. Mon. Wea. Rev., 119, 1954-1978, https://doi.org/10.1175/1520-0493(1991)119<1954: $\mathrm{BASCOH}>2.0 . \mathrm{CO} ; 2$.

Menard, R. D., and J. M. Fritsch, 1989: A mesoscale convective complex-generated inertially stable warm core vortex. Mon. Wea. Rev., 117, 1237-1261, https://doi.org/10.1175/15200493(1989)117<1237:AMCCGI>2.0.CO;2.

Miller, R., 1972: Notes on analysis and severe-storm forecasting procedures of the Air Force Global Weather Center. Air Weather Service Tech. Rep. 200, rev. ed. Air Weather Service, Scott Air Force Base, IL, 184 pp.

Murakami, M., 1990: Numerical modeling of dynamical and microphysical evolution of an isolated convective cloud-The 19 July 1981 CCOPE cloud. J. Meteor. Soc. Japan, 68, 107-128, https://doi.org/10.2151/jmsj1965.68.2_107.

Nakanishi, M., and H. Niino, 2006: An improved Mellor-Yamada Level-3 model: Its numerical stability and application to a regional prediction of advection fog. Bound.-Layer Meteor., 119, 397-407, https://doi.org/10.1007/s10546-005-9030-8.

Newton, C. W., 1967: Severe convective storms. Advances in Geophysics, Vol. 12, Academic Press, 257-303.

Noda, A., and H. Niino, 2010: A numerical investigation of a supercell tornado: Genesis and vorticity budget. J. Meteor. Soc. Japan, 88, 135-159, https://doi.org/10.2151/jmsj.2010-203.

Novlan, D. J., and W. M. Gray, 1974: Hurricane-spawned tornadoes. Mon. Wea. Rev., 102, 476-488, https://doi.org/10.1175/ 1520-0493(1974)102<0476:HST>2.0.CO;2.

Orlanski, I., 1975: A rational subdivision of scales for atmospheric processes. Bull. Amer. Meteor. Soc., 56, 527-530, https://doi.org/10.1175/1520-0477-56.5.527.

Przybylinski, R. W., 1995: The bow echo: Observations, numerical simulations, and severe weather detection methods. Wea. Forecasting, 10, 203-218, https://doi.org/10.1175/15200434(1995) $010<0203$ :TBEONS $>2.0$.CO;2.

Rayleigh, L., 1894: The Theory of Sound. Vol. II. 2nd ed. Macmillan, $522 \mathrm{pp}$.

Roebber, P. J., D. M. Schultz, and R. Romero, 2002: Synoptic regulation of the 3 May 1999 tornado outbreak. Wea. Forecasting, 17, 399-429, https://doi.org/10.1175/1520-0434(2002) $017<0399:$ SROTMT $>2.0 . \mathrm{CO} ; 2$.

Saito, K., and Coauthors, 2006: The operational JMA nonhydrostatic mesoscale model. Mon. Wea. Rev., 134, 1266-1298, https://doi.org/10.1175/MWR3120.1.

Schenkman, A., and M. Xue, 2016: Bow-echo mesovortices: A review. Atmos. Res., 170,1-13, https://doi.org/10.1016/ j.atmosres.2015.11.003.

__ _ _ , and A. Shapiro, 2012: Tornadogenesis in a simulated mesovortex within a mesoscale convective system. J. Atmos. Sci., 69, 3372-3390, https://doi.org/10.1175/JASD-12-038.1.

Sueki, K., and H. Niino, 2016: Toward better assessment of tornado potential in typhoons: Significance of considering entrainment effects for CAPE. Geophys. Res. Lett., 43, 12 597-12604, https://doi.org/10.1002/2016GL070349.

Tamura, Y., and Coauthors, 2016: Development and implementation of Japanese Enhanced Fujita scale. 28th Conf. on Severe Local Storms, Portland, OR, Amer. Meteor. Soc., 6B.5, https://ams.confex.com/ams/28SLS/webprogram/ Paper300864.html.

Tochimoto, E., and H. Niino, 2016: Structural and environmental characteristics of extratropical cyclones that cause tornado outbreaks in the warm sector. Mon. Wea. Rev., 144, 945-969, https://doi.org/10.1175/MWR-D-15-0015.1.

$\longrightarrow$, and - 2017: Structural and environmental characteristics of extratropical cyclones associated with tornado outbreaks in the warm sector: An idealized numerical study. Mon. Wea. Rev., 145, 117-136, https://doi.org/10.1175/MWR-D-16-0107.1.

$\longrightarrow$, and —, 2018: Structure and environment of tornadospawning extratropical cyclones around Japan. J. Meteor. Soc. Japan, 96, 355-380, https://doi.org/10.2151/jmsj.2018-043.

Trier, S. B., and C. A. Davis, 2002: Influence of balanced motions on heavy precipitation within a long-lived convectively generated vortex. Mon. Wea. Rev., 130, 877-899, https://doi.org/ 10.1175/1520-0493(2002)130<0877:IOBMOH >2.0.CO;2.

Wakimoto, R. M., and J. W. Wilson, 1989: Non-supercell tornadoes. Mon. Wea. Rev., 117, 1113-1140, https://doi.org/10.1175/ 1520-0493(1989)117<1113:NST>2.0.CO;2.

, H. V. Murphey, C. A. Davis, and N. T. Atkins, 2006a: High winds generated by bow echoes. Part II: The relationship between the mesovortices and damaging straight-line winds. Mon. Wea. Rev., 134, 2813-2829, https://doi.org/10.1175/ MWR3216.1.

_ ——, A. Nester, D. P. Jorgensen, and N. T. Atkins, 2006b: High winds generated by bow echoes. Part I: Overview of the Omaha bow echo 5 July 2003 storm during BAMEX. Mon. Wea. Rev., 134, 2793-2812, https://doi.org/10.1175/ MWR3215.1.

Weisman, M., and C. A. Davis, 1998: Mechanisms for the generation of mesoscale vortices within quasi-linear convective systems. J. Atmos. Sci., 55, 2603-2622, https://doi.org/10.1175/ 1520-0469(1998)055<2603:MFTGOM>2.0.CO;2.

, C. Evans, and L. Bosart, 2013: The 8 May 2009 superderecho: Analysis of a real-time explicit convective forecast. Wea. Forecasting, 28, 863-892, https://doi.org/10.1175/WAF-D-1200023.1.

Wicker, L. J., and R. Wilhelmson, 1995: Simulation and analysis of tornado development and decay within a threedimensional supercell thunderstorm. J. Atmos. Sci., 52, 2675-2703, https://doi.org/10.1175/1520-0469(1995)052<2675:SAAOTD $>$ 2.0.CO;2.

Xu, X., M. Xue, and Y. Wang, 2015: The genesis of mesovortices within a real-data simulation of a bow echo system. J. Atmos. Sci., 72, 1963-1986, https://doi.org/10.1175/JAS-D-14-0209.1.

Yokota, S., H. Niino, H. Seko, M. Kunii, and H. Yamauchi, 2018: Important factors for tornadogenesis as revealed by highresolution ensemble forecasts of the Tsukuba supercell tornado of 6 May 2012 in Japan. Mon. Wea. Rev., 146, 1109-1132, https://doi.org/10.1175/MWR-D-17-0254.1.

Zhang, D.-L., 1992: The formation of a cooling-induced mesovortex in the trailing stratiform region of a midlatitude squall line. Mon. Wea. Rev., 120, 2763-2785, https://doi.org/10.1175/ 1520-0493(1992)120<2763:TFOACI >2.0.CO;2. 